\title{
CLOUD MANUFACTURING CONCEPT AS A TOOL OF MULTIMODAL MANUFACTURING SYSTEMS INTEGRATION
}

\author{
Grzegorz KŁOSOWSKI \\ Faculty of Management \\ Lublin University of Technology, Lublin, Poland \\ e-mail: g.klosowski@pollub.pl
}

\begin{abstract}
The following article deals with a novel approach to manufacturing in the context of the increasing demand for system and process integration. This integration chiefly applies to concrete facets of manufacturing tasks which must be taken into consideration in the stage of planning and preparation for complex production processes. Those facets are primarily exemplified by order types (such as production, service and cooperative commissions etc.), production models (e.g. discrete and process modeling), product categorization based on established criteria (e.g. production technology, complexity level, used materials and extras, weight, etc.) as well as many other aspects that hold great significance in the automatization of manufacturing processes. When more advanced orders are to be realized, one of the main challenges posed by this situation is the need to accomplish multiple operations which due to their different nature, scope and scale (e.g. varied processing types: heat and plastic treating, machining etc.) have to be conducted by different contractors. In order to address those key problems and reduce the negative impact of multimodality, the author proposes a manufacturing cloud (also known as cloud manufacturing) which is a variant of a groundbreaking, yet well-established concept - cloud computing. This paper presents the chief notions of this method created specifically with integrated multimodal systems and production processes. The author also highlights key problems that should be addressed before this solution can be used in practice.
\end{abstract}

Key words: cloud computing, cloud manufacturing, internet of things, smart computing, artificial intelligence, fuzzy logic, multi-criteria selection, multimodal manufacturing systems.

\section{Introduction}

In the contemporary economy such concept as globalization, automatization, communication, cooperation and virtualization, are gaining significant prominence. They define the key directions of business worldwide and become manifested in information technologies which are based on the ideas of collaboration, Internet of Things and cloud computing [3]. Those notions reflect the current trends in the economic fields of goods and services. Utilizing available methods in novel and original manner within the context of economic practice becomes an imperative. One of the areas which deserves special treatment is the demand for integrating multimodal aspects of economic life.

Firstly, there are many methods which enhance the processes that occur in various manufacturing and service systems. The challenge there lies in adjusting the existing and tested solutions to new fields of economic life (e.g. different sectors of industry). For example, a task scheduling method us normally used in ordering microprocessor operations of a $\mathrm{CPU}^{1}$ which works in many technical devices can be applied in modern workshop. Using the same CPU and drivers it is possible to schedule individual tasks and set them to different machine tools and workstations. Secondly, in case of complex goods, their production involves multiple and varied processes. Frequently, this forces a main contractor to categorize all the processes and outsource some of them to subcontractors. Seeking a capable contractor entails organization of collaboration (e.g. signing an agreement), the delay in fulfilling the commissioning, the reduction of cost-effectiveness, the partial loss of control over the order, the raise of anxiety over meeting the deadline. These setbacks are termed as multimodality of manufacturing systems. The problem of integrating such systems into coherent whole can be addressed by cloud manufacturing whose analysis is the subject of this paper.

\footnotetext{
${ }^{1}$ Central Processing Unit or occasionally Central Processor Unit
} 


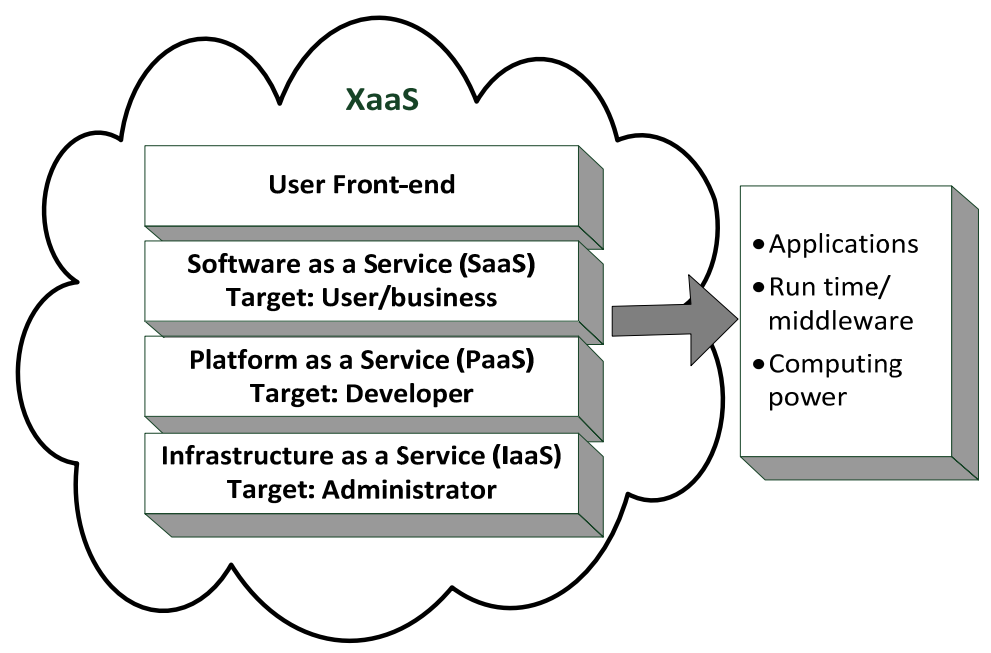

Figure 1. Cloud computing layers and services (source: self study on the basis of [34])

\section{2}

\section{Cloud manufacturing and cloud computing}

The concept of cloud manufacturing originates from cloud computing - an idea which has been in practical use for ten years. This approach enables users to access software and technological services (e.g. email, file repository, file converters, text editors) using only a working Internet connection and a web browser. One of the chief aspects of this concept is the distributed information storage. The information is not stored in a concrete, local hard drive, but in a vague, undefined, distributed environment of a network, called a cloud. Physically the files are located on specially structured drives, within so called data centers. This way of storing information and software protects it from unforeseen damages since all the data in the cloud is simultaneously copied to other locations. Normally datacenters are in great distance from each other and thus the physical destruction of one data center does not cause any loss of information. Evidently, the cloud storage model is a secure solution as far as data safety is concerned. It also offers a very convenient way of administrating data, since the administrator is freed from the obligation of preparing backup copies.

According to National Institute of Standards and Technology (NIST) [21] cloud computing can be defined as a model for enabling ubiquitous, convenient, ondemand network access to a shared pool of configurable computing resources (e.g., networks, servers, storage, applications, and services) that can be rapidly provisioned and released with minimal management effort or service provider interaction. Another popular approach defines cloud computing as a large-scale distributed computing paradigm that is driven by economies of scale, in which a pool of abstracted, virtualized, dynamically-scalable, managed computing power, storage, platforms, and services are delivered on demand to external customer over the Internet [8]. The above said definitions reflect key features of cloud computing: network collaboration, scalability, flexibility, versatility and straightforward management. All of these factors make cloud computing technologies easy to implement in various walks of economic life. The concept of cloud computing assumes that the interaction between a service provider and a user is based on services. Those services, depending on their character, can be divided into three categories: SaaS (Software as a Service), PaaS (Platform as a Service) and IaaS (Infrastructure as a Service) [31]. Generally, all the services offered through cloud computing model can be defined as "everything as a service" (XaaS) (see Fig. 1). These terms together form a multilayered cloud computing system. The infrastructure layer (IaaS) standardizes a number of processes realized in the cloud: data processing, storage, networking etc. In this model a cloud provider enables his clients (users) to install and launch an operating systems and utility software. PaaSis the middle layer in the hierarchy.

It offers tools necessary to build one's own software as well as environments which allow it to be tested, implemented, hosted and developed further. The highest layer include computing hierarchical structure is SaaS this model enables users to take advantage of a ready, compiled utility application. 


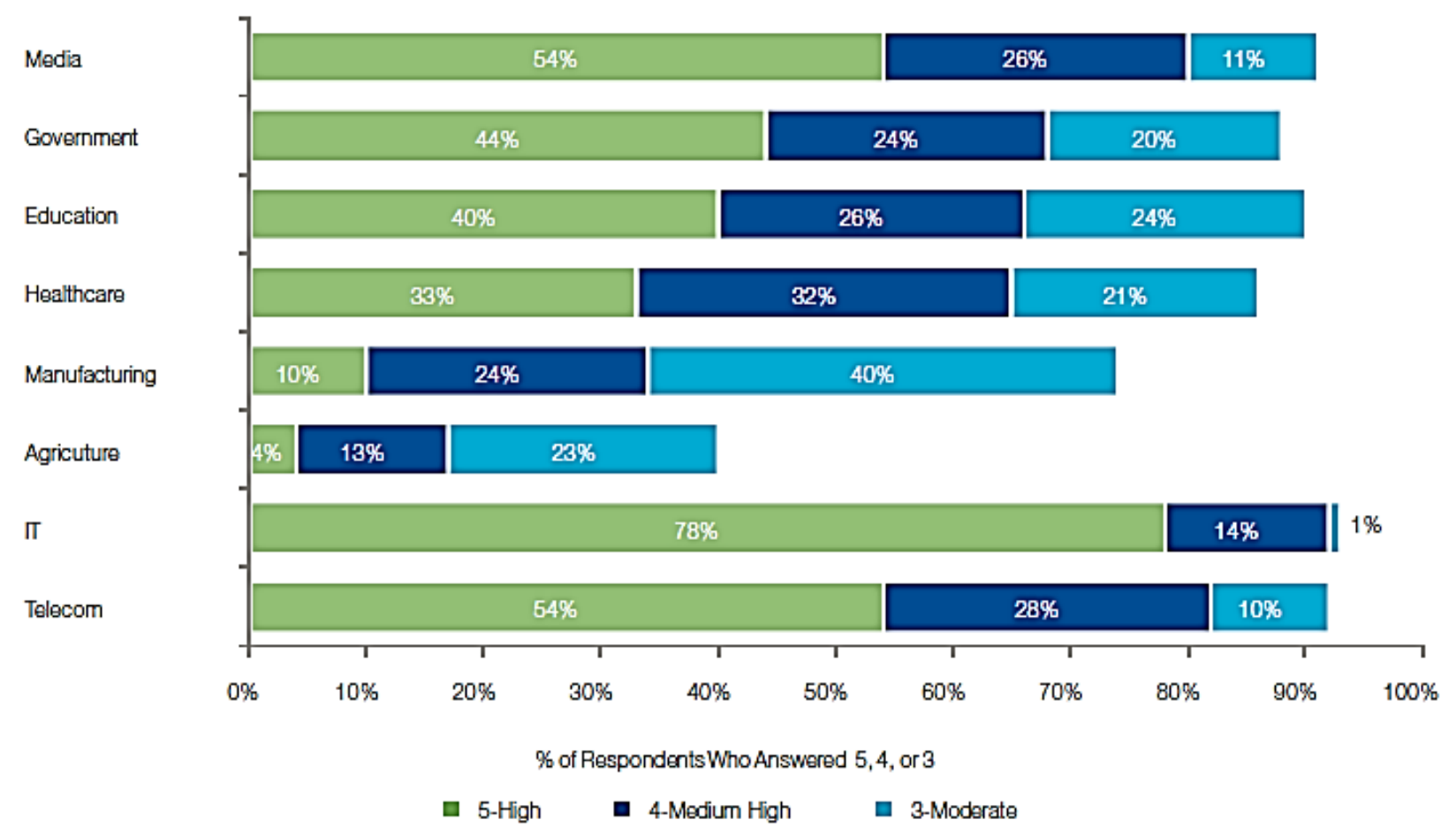

Figure 2. Multimodal industries which are most likely to be impacted by cloud computing (source [33])

\section{$3 \quad$ Multimodal industrial integration}

The value of each method is determined on account of certain evaluation criteria. The concept of cloud computing is ranked highly in the field of Information and Communication Technology (ICT) due to a number of advantages which directly influence the quality and the way of performing information processing operations. This idea itself, however, is universal enough to be applied to other facets of social and economic life (see Fig. 2). The only problem this raises is the need to create discrete informational and organizational models to apply for every field of expertise. Precisely due to varied models cloud computing enjoys different levels of applicability in a number of fields of life.

The current technological level of IT does not permit creating a universal software based upon the cloud platform whose versatility would be sufficient to use it interdisciplinary. However, the multimodality of the fields of use caused cloud computing to be adapted in a number of social and business spheres, e.g. media, education, healthcare, manufacturing, telecommunication etc. (see Fig. 2). The challenge of adjusting cloud computing to the manufacturing challenges requires a new, original service model that would take into ac- count many precise assumptions and which would allow the business to tackle many problems specific to concrete lines of industry [34]. Bearing this in mind, cloud manufacturing can be seen as an integrated set of methods which deal with the realization of production process and production services. The concept of cloud manufacturing involves the use of cloud infrastructure in each phase of the production process. (see Fig. 3). Cloud manufacturing is often mistakenly linked to the notions of networked manufacturing, Internetbased manufacturing or distributed manufacturing. These three concepts assume the integration of distributed resources in order to perform a single production task ([20], [26]), whereas the idea of cloud computing permits the realization of multiple tasks of this kind. According to the principles of cloud manufacturing distributed production resources can be integrated and integrated production resources distributed between a number of businesses. Thus, analogically to the concept of cloud computing, cloud manufacturing can be defined as a model for enabling ubiquitous, convenient, on-demand network access to a shared pool of configurable manufacturing resources (e.g., manufacturing software tools, manufacturing equipment, and manufacturing capabilities) which can be rapidly provisioned and released with minimal management effort or service provider interaction [34]. 


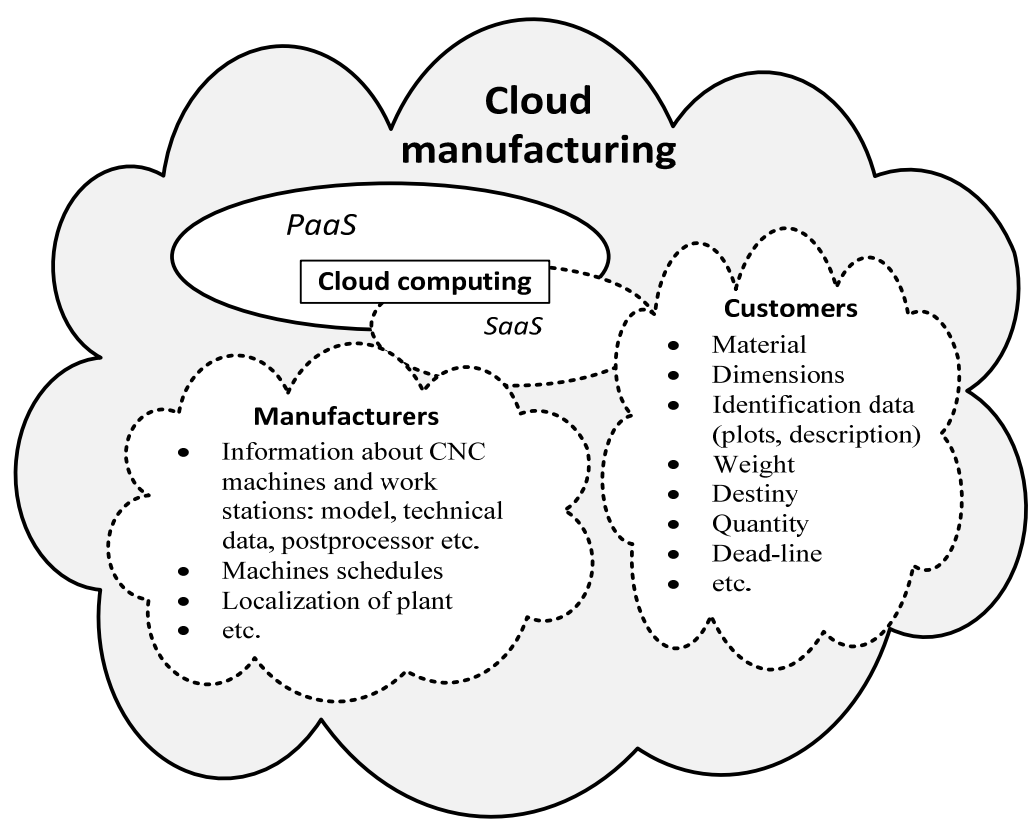

Figure 3. The concept of cloud manufacturing (source: self-study)

The practical realization of the presented concept requires an enterprise to create a web portal which works as a highly automated storage of production orders and production capabilities of each of the parties involved in the manufacturing process. This portal could enable the prospective customers to register and fully describe a desired item. The portal would also register businesses capable of utilizing particular $\mathrm{CNC}$ machine stocks.

Having CNC machine tools is critical, since a machine tool typically has access to LAN/WAN networks. Owing to this approach, the web portal that implements cloud manufacturing could have real-time access to all the necessary information directly from all manufacturing environments.

Furthermore this portal could give access to MRP/ERP class systems as a service [25], whose main task would be to plan all the jobs for each machine tool registered in the cloud in advance. This step is necessary in order to properly prepare the automatic realization of a given tasks.

\section{$4 \quad$ Architecture of cloud manufacturing system}

The basic structure of the highlighted cloud manufacturing model comprises two sides (manufacturer's and customer's) and six layers. The manufacturer's side layers are composed of: application layer, global service layer, virtual service layer and manufacturing resource layer. On the other hand the customer's side layers are: manufacturer selection layer and order description layer (see Fig. 4). The application layer in user domain permits producers (user-manufacturers) to create their own software components characterized by modularity, mobility and pluggability (the readiness to attach the given component to an entire system, increasing its functionality).

The application layer is implemented according to SaaS model [30] as a web run-time environment, which permits the users to build new computer software as well as allows its testing (simulation) before its integration with the system. Once the new components have been examined they can be incorporated into the system (in the global service layer) as run-time modules. The provider domain contains two layers, which are directly associated with a production business. The manufacturing resource layer comprises the software used to stock-take the resources available to concrete production enterprises. 


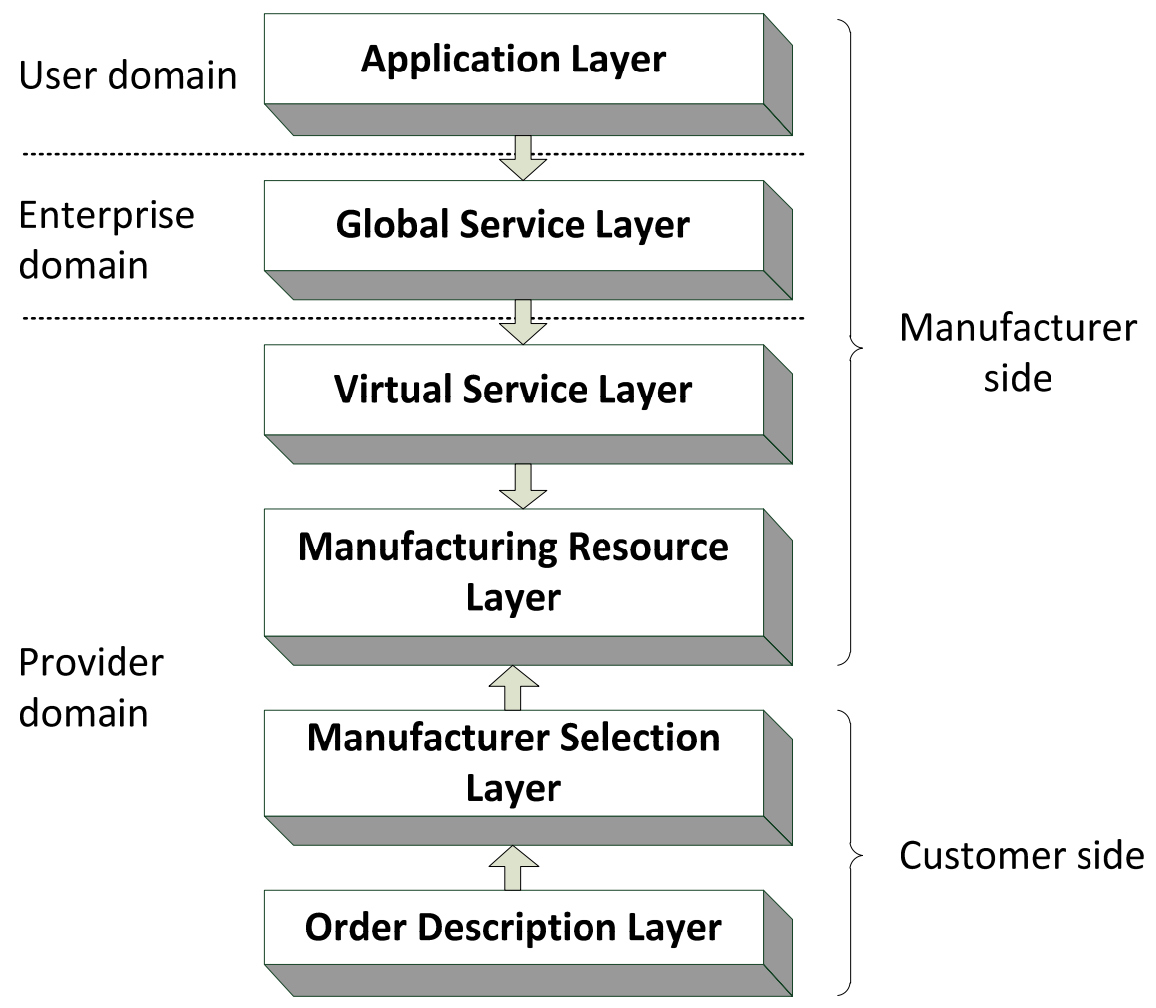

Figure 4. Layered framework of cloud manufacturing system (source: self-study on the basis of [34])

The most critical are the information on the ready-touse CNC machine tools and the current state of orders from the given field. Manufacturing service layer is composed of tools that identify production resources, permit their virtualization and relocate them in a network as cloud manufacturing services. It needs to be stressed that all of these tasks are much more difficult to implement in cloud manufacturing model than in cloud computing. The informational tools in the provider domain have other, significant uses. One of the basic functionalities of cloud manufacturing is matching the right providers with concrete production orders, so apart from manufacturer's side, a cloud manufacturing platform should also account for the client's side. For that reason, two layers of provider domain in this platform work also for a client.

The first one - Order Description Layer - enables users to give a detailed description required for the producers to properly fulfill the task. The order is taken through an interactive form, where the questions given depend on the answers provided beforehand. This form constitutes a method of initiating a formalized dialogue by the system with the client. The goal of the dialogue is to determine the subject of an order. The data collected in this way should help to identify the construction of the item and required technology as well as determine expected limitations, customer's special requirements and other information which would impact the appraisal of the order. Moreover, a user should be able to attach CAD or CAM file with additional details. On account of the high level of complexity involved in identifying the problem a manufacturer selection layer was created. This layer consists of software responsible for determining technological operations required for a given order, selecting the correct providers, and if necessary supplying a technological path (the order of operations and providers in a technological chain).

\section{Deployment problems}

This chapters deals with the most common problems that must be addressed before the concept of cloud manufacturing can be implemented. Furthermore, it gives a viable solution to one of the more difficult challenges - the multi-criteria selection of production service providers. The solution consist of two steps. The first phase involves the system selecting all capable machine tools, disregarding their physical location. The second phase is the client's choice of a production or a group of production providers for the manufacturing task. 


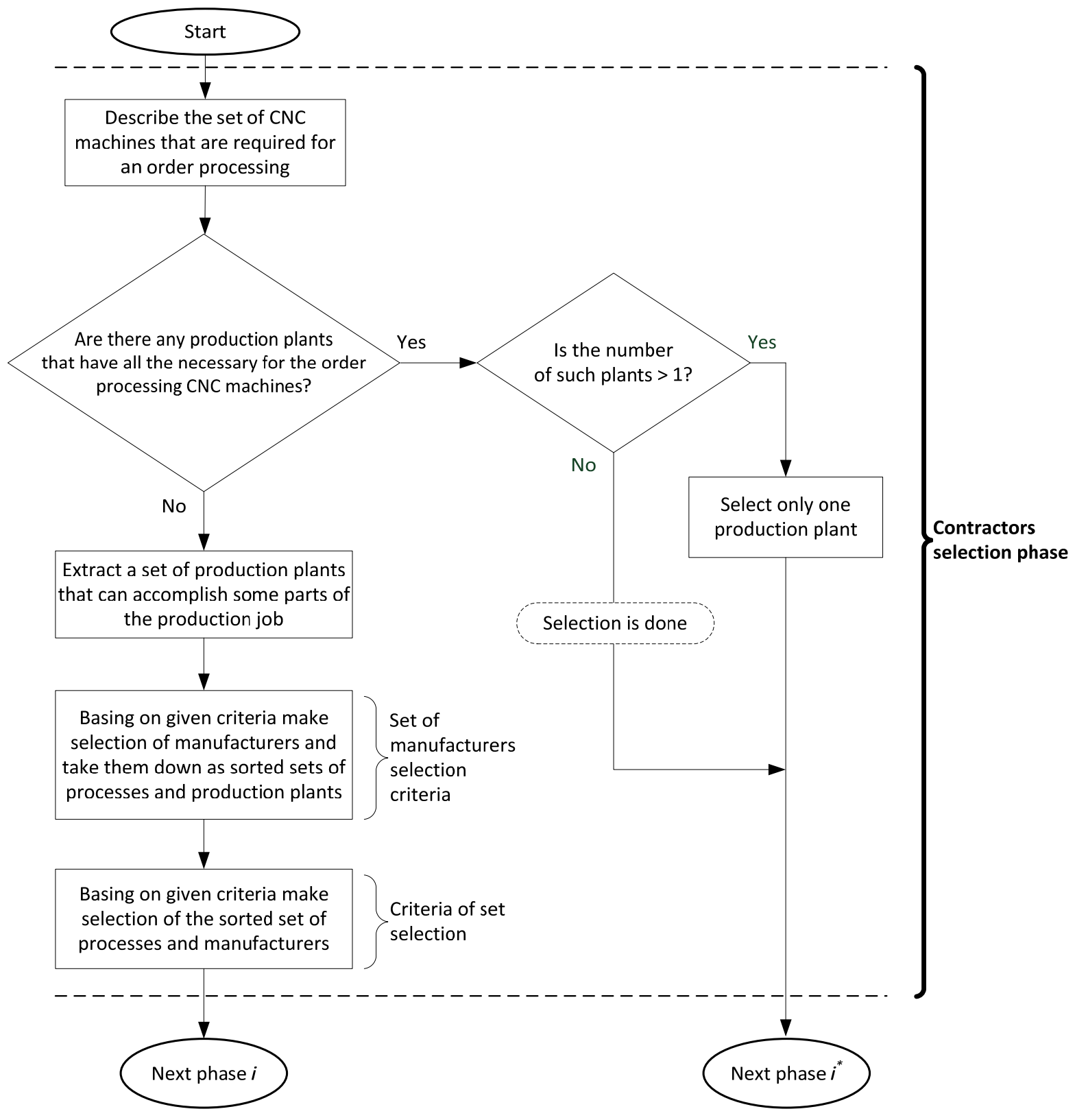

Figure 5. The algorithm for manufacturer selection in cloud manufacturing model (source: self-study)

\subsection{Key requirements of cloud manufacturing systems}

The cloud manufacturing presents a number of problematic issues, which require adequate solutions. Those issues include:

- preparing an interactive form that can be used to define manufacturing commissions,

- preparing the mechanism that enables selection of a qualified provider for a defined manufacturing order,
- preparing interfaces with a real-time access to manufacturing resources of production facilities (the potential contractors),

- preparing MRP/ERP class system that could provide services in SaaS model,

- adjusting the web portals to different lines of industry,

- data security and backup as well as adapting to international law in case of international character of the project (e.g. when the client and the provider are based in different countries), etc. 


\section{STAGE I}

Acquisition and processing of information about machine tools, representation of design knowledge, development of technological assumptions for the product to be machined

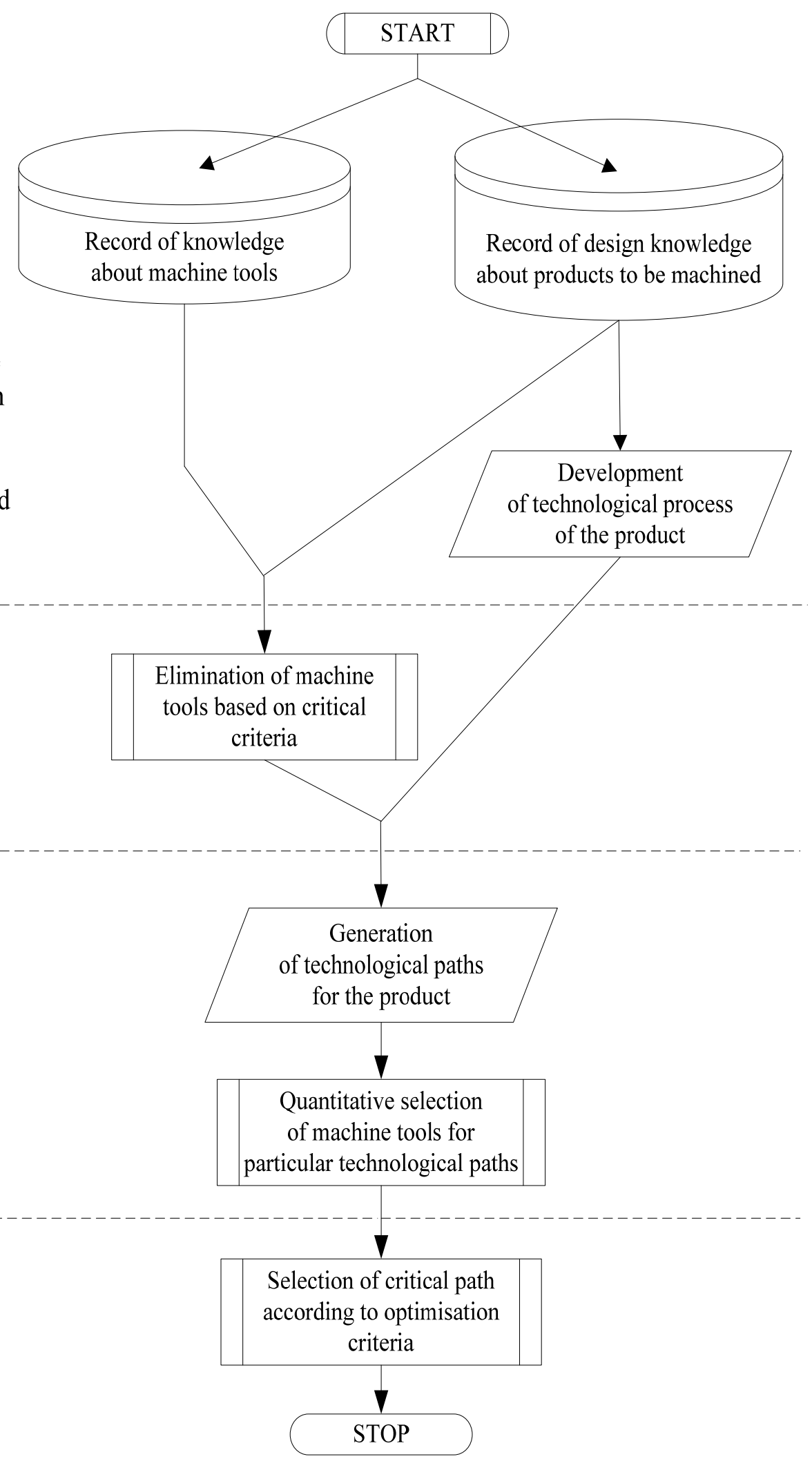

Quantitative selection of machine tools for particular technological paths

\section{STAGE II}

Elimination of machine tools that do not meet the critical technological and organizational conditions

\section{STAGE III}

Development of possible variants of machining of the product quantitative choice of machine tools for the particular variants

\section{STAGE IV}

Optimization analysis of the particular variants selection of machine tools in accordance with the adopted optimisation criteria
Selection of critical path ccording to optimisation criteria

Figure 6. Algorithm of machine tool selection (source: self-study on the basis of [9]) 


\subsection{Selection of manufacturers}

The chief argument that supports the efficacy of cloud manufacturing is the high level of automatization which characterizes many processes on the line clientprovider during the realization of business transactions. The most serious issue is finding an effective algorithm which could efficiently match manufacturing providers with specific production tasks. Complex orders may involve many contractors that are to perform multiple stages of a manufacturing process. This requires from them to be identified by the system and selected in an appropriate order determined by a technological route (see Fig. 5). Provider identification involves determining what kind of manufacturing tools (mainly $\mathrm{CNC}$ machine tools) are required by the order. Next, user should select particular machine tool from among all of the machines registered in a manufacturing cloud. During this selection many criteria are taken into consideration. First and foremost, the selection should account for critical criteria-to rule out all machine tools which are incapable of accomplishing any of the identified technological operations. The second group of criteria should focus on minimizing the manufacturing time and cost. One significant aspect which factors in this choice is the close proximity of the machine tools returned by the search. An ideal solution would be to find a single enterprise with extensive enough assets to perform all the necessary technological operations on-site. If it turned out to be impossible, the algorithm should group the prospective contractors so that the number of the parties involved in the process would be minimal. As cloud manufacturing platform develops there could appear new sets of more sophisticated criteria such as the cost and time of transportation of the produced elements, work-time schedule of individual enterprises, the estimated experience of the contractor in realizing similar projects, etc.

\subsection{Algorithm of machine tool selection}

As mentioned before a contractor search may return results with many different parties involved at different stages of order realization which will require cooperation with one or more enterprises. The number of the parties involved in the project depends on the kinds of machine tools needed to complete it. In case of versatile CNC centers, many operations can be finalized on-site, which reduces the number of required machines in a technological path. A modified algorithm normally used in machine tools working in a flexible manufacturing systems can be used as a basis for machine selection. (see Fig. 6) ([9], [10], [11] and [12]).

This algorithm consists of four stages. The first stage comes down to gathering and processing the data on machine tools, representation and form of construction knowledge and technological plan of a constructed item. The data on available machine tools are constantly monitored owing to the abovementioned MT Connect standard. The representation of knowledge ought to fulfill two essential objectives:

- formalization of the parts required in processing in the form on input data for a data management system. This allows the system to match the construction characteristics of the parts with the parameters of the machine tools.

- efficient data processing, which automatizes the process of machine tool selection, matching them with appropriate goods which can be create in the cloud manufacturing environment.

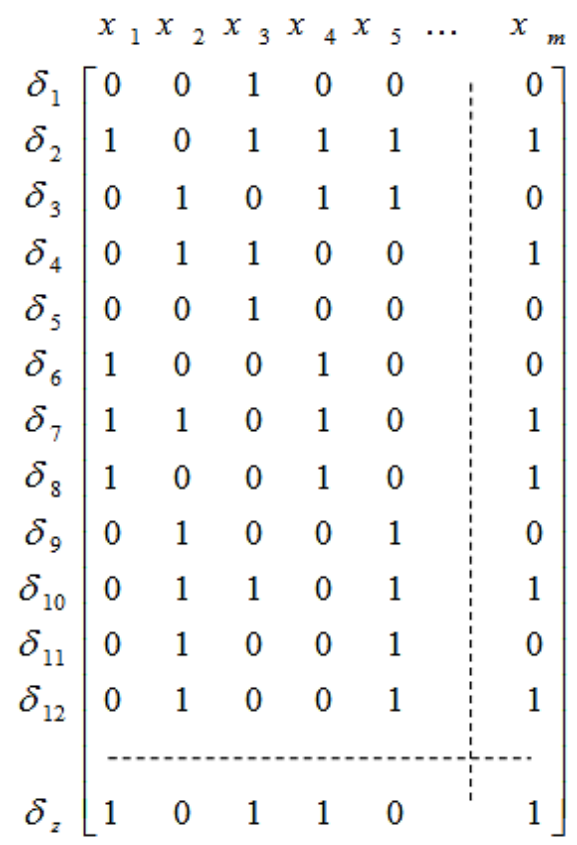

where:

$\mathrm{x}_{1}, \mathrm{x}_{2}, \ldots, \mathrm{x}_{\mathrm{m}}$ are the machine tools from set $\mathrm{X}$,

$\delta_{1} \ldots \delta_{\mathrm{z}}-$ successive cuts during manufacturing process, 1 - "one" in the matrix means possibility of machining specified cut on the specified machine tool,

0 - "zero" means such possibility does not exist.

Figure 7. Matrix of technological capabilities in relation to the particular product or part (source: self-study on the basis of [12]) 
The second stage involves elimination of all machine tools that fail to fulfill technical and organizational requirements. Examples of these critical criteria include: the ability to use numerical control, the maximal strain of the machine's table, maximal dimension of the item to be processed by the machine, the maximal dimensions of the hooks and grapples needed to attach the item, etc. The result of phase two can be translate into adjacency matrix of machine tools and operations (see Fig. 7). This matrix should contain the information about all available machine tools and all the operations needed do create a desired item. If there are no 0 values in a given column of the matrix, it means that all operations can be completed using a single machine tool. A column filled with zero values signifies that the picked machine tool cannot complete any of desired technological operations with respect to the given manufacturing task. Another extreme example: if there are only 0 values in the given row, it means that the set of machine tools has insufficient capability to complete the manufacturing order.

The third stage is preparing all the possible processing variants of the item and selecting the cost-effective number of machine tools for each possibility.

The last phase - stage four - entails optimizing each of the variants and matching machine tools with predefined optimization criteria. The procedure of choosing an appropriate technological path has been presented on a straightforward example. The columns of a [3x3] capacity requirements matrix $\mathrm{A}_{\mathrm{mz}}$ contain information about available tools, and its rows the required technological operations.

$$
A_{m z}=\left[\begin{array}{ccc}
1 & 0 & 1 \\
0 & 1 & 0 \\
1 & 1 & 1
\end{array}\right]
$$

The value 1 signifies that a given machine tool can carry out the required process; 0 means the opposite. The available technological routes go down the columns in the $A_{m z}$ matrix, along all 1 digits in different columns. Each 0 in a column means that the machine tool needs to be changed which may also entail changing the service provider. Thus the most desirable route is the one with the least number of such changes. In the presented example there are six possible technological routes (see Table 1).
Table 1. Developing technological paths (source:self-study on the basis of [12])

\begin{tabular}{|c|c|c|}
\hline Solution No. & $\begin{array}{c}\text { Technological } \\
\text { paths }\end{array}$ & $\begin{array}{c}\text { No. of } \\
\text { changes }\end{array}$ \\
\hline $\mathrm{P}_{1}$ & $1-2-1$ & 2 \\
\hline $\mathbf{P}_{\mathbf{2}}$ & $\mathbf{1 - 2 - 2}$ & $\mathbf{1}$ \\
\hline $\mathrm{P}_{3}$ & $1-2-3$ & 2 \\
\hline $\mathrm{P}_{4}$ & $3-2-1$ & 2 \\
\hline $\mathbf{P}_{\mathbf{5}}$ & $\mathbf{3 - 2 - 2}$ & $\mathbf{1}$ \\
\hline $\mathrm{P}_{6}$ & $3-2-3$ & 2 \\
\hline
\end{tabular}

Having analyzed all the available routes and a number of changes in each one it can be concluded that there are two equally efficient solutions: In $\mathrm{P}_{2}$ and $\mathrm{P}_{5}$ routes there is only one change. The further stages of selection which lead to the choice of a single solution can be based on other algorithms.

For example, one can assign weights to particular characteristics of a machine or an manufacturing enterprise which owns a number of them. Owing to this method each alternative technological route will be additionally marked with a parameter, which reflects the summary value of each path. As a result it is easy to determine the efficiency of each solution which can help identify the best service providers

\subsection{Fuzzy inference system of manufacturers selection}

Due to a significant progress in information technologies it is relatively easy (i.e. fast and cheap) to build a decision making system using the instruments based on artificial intelligence. The example that will be discussed herein is a fuzzy inference system (FIS) whose objective is to assess potential service providers (contractors). In contrast with previously highlighted method of matching tasks with appropriate machine tools, the discussed FIS controller would be useful at the second stage of the selection. The first stage determined a set of technological paths which constituted balanced solution. The next phase of the procedure results in the final solution based on the criteria established in respect to an enterprise, as opposed to separate machine tools. 


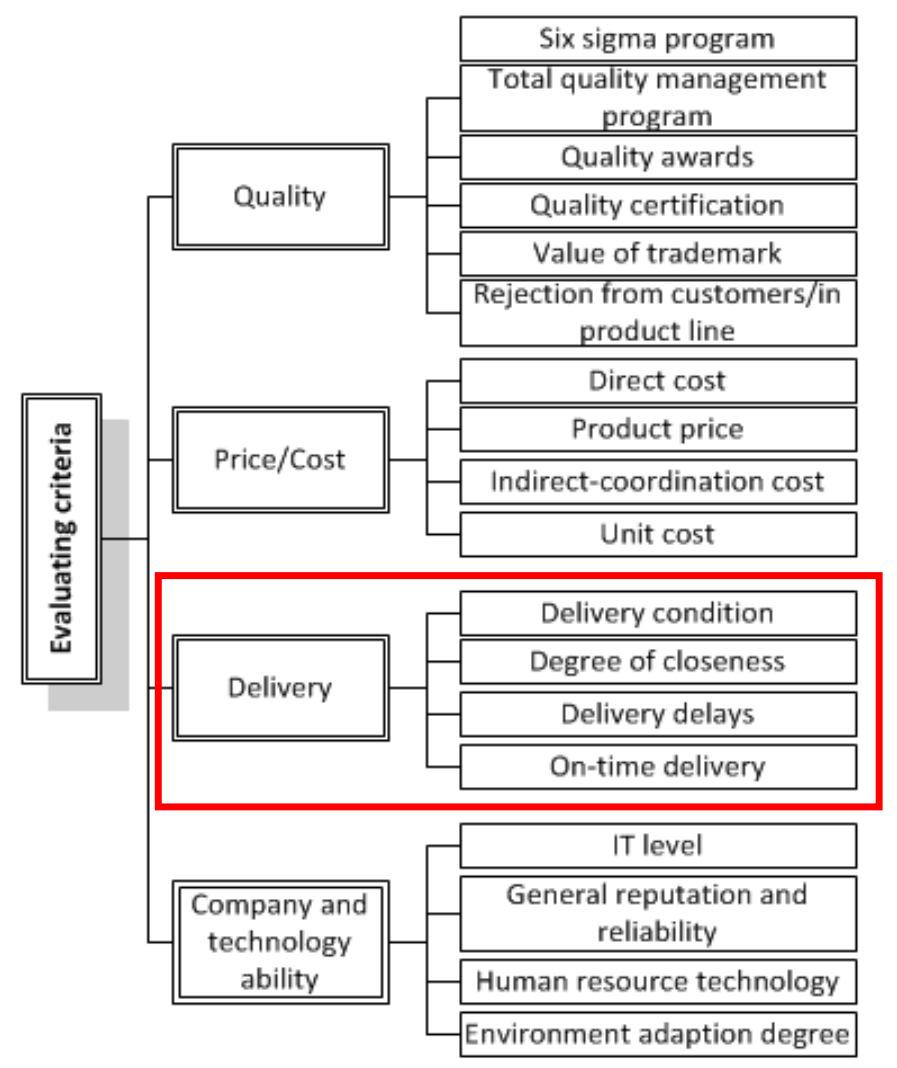

Figure 8 . Hierarchy of evaluating criteria and sub-criteria to fuzzy-based computing process (source: self-study on the basis of [19])

The key advantage of fuzzy logic is the fact that it can be used to describe any phenomena with qualitative or quantitative variables. Quantitative variables are objective, easy to measure and credible. In contrast, qualitative variables are frequently subjective as they depend on the opinions of individual persons who have judged them. For this reason qualitative variables have linguistic form (descriptions). A fuzzy set is an area where the level of membership with the set is described by a real number from the range between 0 and 1 . A fuzzy set is defined by a membership function, which associates objects form the given discipline with a numerical value that describes their level of membership with the set. The membership function $\tilde{A}$ is defined as $\mu_{\widetilde{A}}$, while the value of membership is defined by $\mu_{\widetilde{A}}(\mathrm{x})$. A linguistic variable reflects qualitative information with a description or a membership function - in the latter case it carries quantitative meaning. The fuzzy set $\widetilde{A}$ in $X$ is determined by a membership function, which is defined as $\mu_{\widetilde{\mathrm{A}}}(\mathrm{x}): \mathrm{x} \in \mathrm{X} \rightarrow[0,1]$, where $\mathrm{X}$ is a domain space. Depending on the context of $\mathrm{x}$, the membership function may be interpreted differently. For example, the membership value of delivery $\mathrm{x}$, which belongs to a fuzzy set of preferences can be subjectively estimated from client's satisfaction level - the person who receives the parcel. The membership function determines the intensity of preferences of the person who assesses the benefit from the received shipment. According to the fuzzy set theory it is possible to use constant values of the membership function from the $(0,1)$ interval as illustrated in formula 1 [22].

$$
\mu_{\widetilde{\mathrm{A}}}(\mathrm{x})=\left\{\begin{array}{rl}
1 & \text { iif } \quad \mathrm{x} \in \widetilde{\mathrm{A}} \\
0 & \text { iif } \mathrm{x} \notin \widetilde{\mathrm{A}} \\
\mathrm{p} & 0<p<1 \\
\text { if } \mathrm{x} \text { p partially belongs to } \widetilde{\mathrm{A}}
\end{array}\right.
$$

In the fuzzy set theory all equations are formed with a membership function. Taking into account the value of an input parameter, the output of an membership function returns "the degree of truth". All of the elements in a fuzzy set present a certain degree of membership which is determined by the membership function. As we remember the membership range is an interval between 0 and 1 , where 0 signifies that the element does not belong to the fuzzy set, 1 means full membership and any other value means partial membership [37]. The fuzzy controller used in this work has been based upon Mamdani's model. 


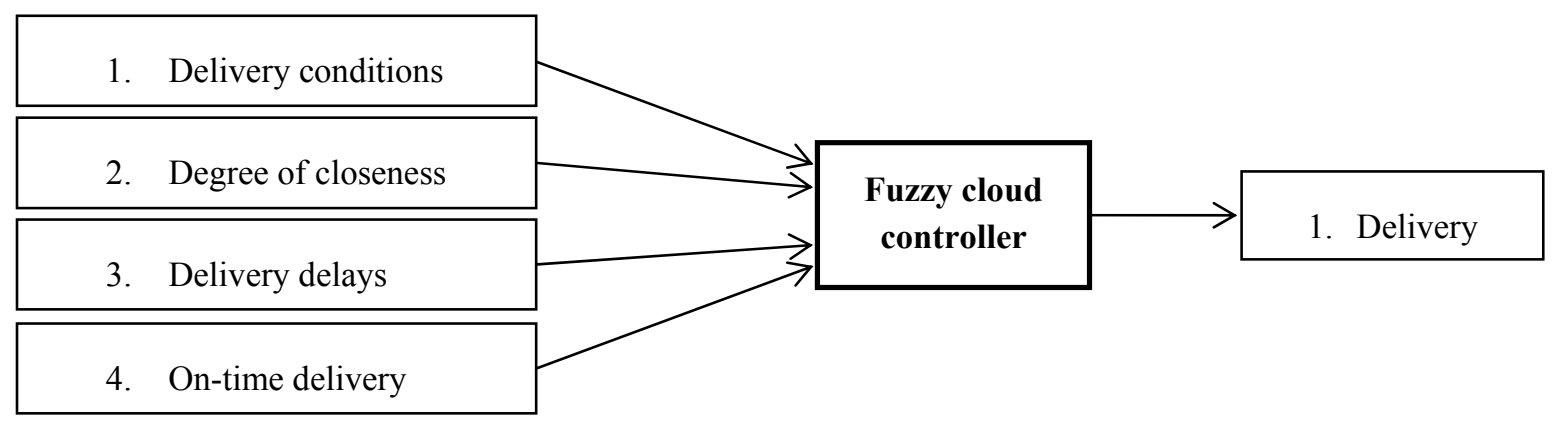

Figure 9. Fuzzy controller: inputs and output (source: self-study)

The controller has a set of inputs, which correspond to the criteria that define the selection of a contractor. In the test scenario a number of chief criteria defining the selection of the best provider were identified:

- Quality - the level of how well made an order item is,

- Price/Cost - the criterion that accounts for the overall price,

- Delivery - the criterion that accounts for the issues connected with the delivery of a product,

- Company and technological capacity - this criterion accounts for technological capabilities of the enterprise and its prestige.

All of those criteria are defined as variables with the values from the interval of $(0,1)$ (see Fig. 8). The numerical value of each of the criteria generates a separate fuzzy logic module. As a result we determine the vector of numerical values which correspond to individual evaluation criteria of the manufacturing company. Those values can be totaled up to receive the figure which reflects the level of attractiveness of particular business. In order to link the evaluation indicator to the actual condition of the given enterprise, each criterion can have weights ascribed to them. This will diversify the influence of criteria on the final score.

It should be noted that owing to fuzzy logic (also known as soft computing method) it is possible to take into consideration not only the quantitative criteria such as price, but also qualitative criteria which are difficult to measure. A fuzzy logic controller which has been build in accordance with the above said method is characterized by modular construction where every module is responsible for identifying the value of a separate criterion. For example, in this hypothetical scenario the quality of delivery service is measured by Delivery criterion. As established before, the eval- uation (score) generated in this criterion takes the form of a number from $(0,1)$ interval, where 0 means lack of capacity for delivery and 1 signifies full delivery capacity.

Delivery criterion was conditioned by four fuzzy variables: Delivery conditions, Degree of closeness, Delivery delays, On time delivery. All of these fuzzy variables are also linguistic variables and are the subcriteria of the Delivery parameter (see Fig. 9).

It can be clearly observed that these four variables are qualitative in character. Usually this presents a considerable challenge, as those parameters have to be converted to a scalar form. In case of a fuzzy controller the first phase of data processing involves "fuzzification" of variable values which are given as numbers from a pre-determined scale. In this example the scale of the input variables corresponds to the scale of output variables - all values are real numbers set between $(0,1)$.

All the four input variables are "fuzzied" with the same membership function in a triangle wave, according to formula 2 .

$$
\begin{aligned}
& \mu_{\widetilde{A}}(x, a, b, c) \\
& =\max \left(\min \left(\frac{x-a}{b-a}, \frac{c-x}{c-b}\right), 0\right)
\end{aligned}
$$

where: $\mathrm{a}, \mathrm{b}, \mathrm{c}-$ are the parameters that determine the exact location of the three angles of the $x \in R, 0 \leq x \leq 1$ triangle.

All of the membership functions of the Delivery input variable take the form of a triangle wave and differ only in $\mathrm{a}, \mathrm{b}$ and $\mathrm{c}$ parameters. The plot of the membership function correspond to five linguistic variables which determine the degree of membership of the output variable for the given fuzzy set. The shape of each progress of all membership functions for every input variable depends on $\mathrm{a}, \mathrm{b}$ and $\mathrm{c}$ parameters, which has been presented in Table 2. The inserted values correspond to the function graph in Fig. 10 - 14. 
Table 2. The parameters associated with the triangular membership functions of Delivery (source: self study)

\begin{tabular}{|l|c|c|c|}
\hline \multirow{4}{*}{1. Delivery conditions (input) } \\
\hline \multirow{2}{*}{$\begin{array}{c}\text { Membership } \\
\text { functions }\end{array}$} & \multicolumn{3}{|c|}{ Parameters } \\
\cline { 2 - 4 } & $\mathrm{a}$ & $\mathrm{b}$ & $\mathrm{c}$ \\
\hline Very bad & 0 & 0 & 0.3 \\
\hline Bad & 0,1 & 0,3 & 0,5 \\
\hline Fair & 0,3 & 0,5 & 0,7 \\
\hline Good & 0,5 & 0,7 & 0,9 \\
\hline Very good & 0,7 & 1 & 1 \\
\hline
\end{tabular}

\begin{tabular}{|l|c|c|c|}
\hline \multirow{4}{*}{ 2. Degree of closeness (input) } \\
\hline \multirow{2}{*}{$\begin{array}{c}\text { Membership } \\
\text { functions }\end{array}$} & \multicolumn{3}{c|}{ Parameters } \\
\cline { 2 - 4 } & $\mathrm{a}$ & $\mathrm{b}$ & $\mathrm{c}$ \\
\hline Very far & -0.25 & 0 & 0.25 \\
\hline Far & 0 & 0,25 & 0,5 \\
\hline Average & 0,25 & 0,5 & 0,75 \\
\hline Close & 0,5 & 0,75 & 1 \\
\hline Very close & 0,75 & 1 & 1,25 \\
\hline
\end{tabular}

\begin{tabular}{|l|c|c|c|}
\hline \multicolumn{4}{|c|}{ 3. Delivery delays (input) } \\
\hline \multirow{2}{*}{$\begin{array}{c}\text { Membership } \\
\text { functions }\end{array}$} & \multicolumn{3}{|c|}{ Parameters } \\
\cline { 2 - 4 } & $\mathrm{a}$ & $\mathrm{b}$ & $\mathrm{c}$ \\
\hline Very big & $-0,25$ & 0 & 0,25 \\
\hline Big & 0 & 0,25 & 0,5 \\
\hline Average & 0,25 & 0,5 & 0,75 \\
\hline Small & 0,5 & 0,75 & 1 \\
\hline Very small & 0,75 & 1 & 1,25 \\
\hline
\end{tabular}

\begin{tabular}{|l|c|c|c|}
\hline \multicolumn{4}{|c|}{ 4. On-time delivery (input) } \\
\hline \multirow{2}{*}{$\begin{array}{c}\text { Membership } \\
\text { functions }\end{array}$} & \multicolumn{3}{|c|}{ Parameters } \\
\cline { 2 - 4 } & $\mathrm{a}$ & $\mathrm{b}$ & $\mathrm{c}$ \\
\hline Very bad & $-0,25$ & 0 & 0,25 \\
\hline Bad & 0 & 0,25 & 0,5 \\
\hline Average & 0,25 & 0,5 & 0,75 \\
\hline Good & 0,5 & 0,75 & 1 \\
\hline Very good & 0,75 & 1 & 1,25 \\
\hline
\end{tabular}

\begin{tabular}{|l|c|c|c|}
\hline \multicolumn{4}{|c|}{ 5. Delivery(output) } \\
\hline \multirow{2}{*}{$\begin{array}{c}\text { Membership } \\
\text { functions }\end{array}$} & \multicolumn{3}{|c|}{ Parameters } \\
\cline { 2 - 4 } & $\mathrm{a}$ & $\mathrm{b}$ & $\mathrm{c}$ \\
\hline Very poor & $-0,25$ & 0 & 0,25 \\
\hline Poor & 0 & 0,25 & 0,5 \\
\hline Fair & 0,25 & 0,5 & 0,75 \\
\hline Good & 0,5 & 0,75 & 1 \\
\hline Excellent & 0,75 & 1 & 1,25 \\
\hline
\end{tabular}

As a consequence each of the four input variables is being "fuzzied" with five adequately matched membership functions. In this case a triangular wave was used, but such parameters as: the values of membership functions, their type and their progress should be selected by an experienced designer. The designer should master the techniques of fuzzy logic as well as possess the practical knowledge from the discipline that factors in the issue in question. There are certain standards and operation schemes, which have been used practically and can serve as a general behavior model in designing Fuzzy Interface Systems. Nonetheless, due to the lack of firm and unequivocal methodical rules each instance of constructing a system that is based on fuzzy logic ought to be considered individually. 


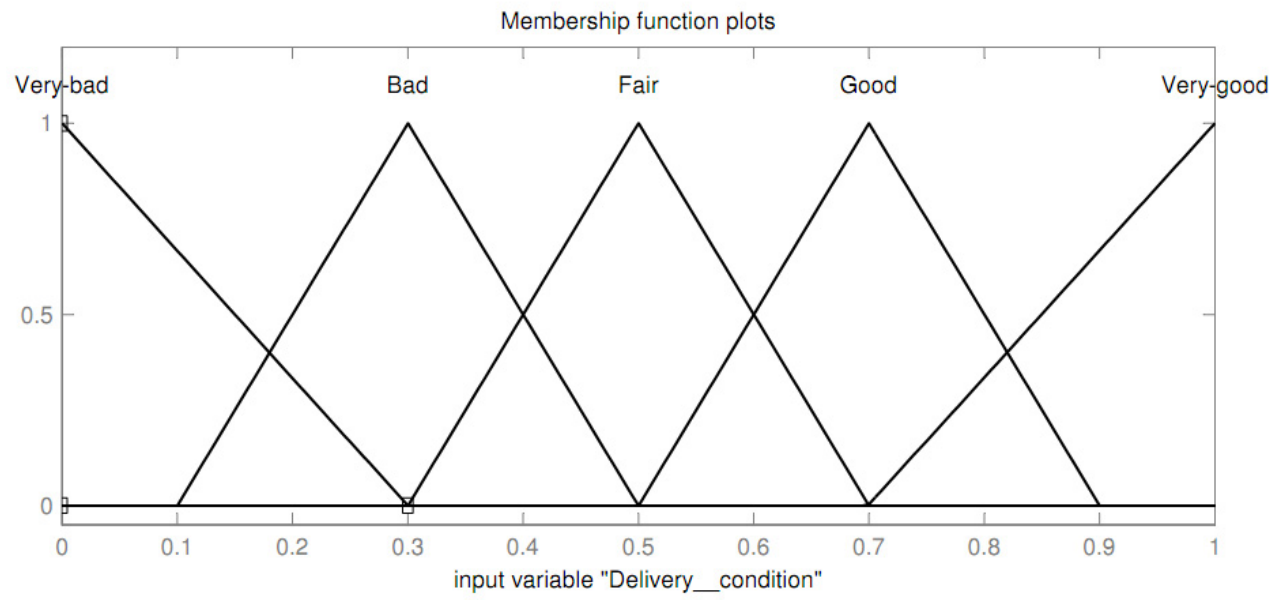

Figure 10. The linguistic terms of Delivery condition fuzzy input variable and membership function plots (source: self-study)

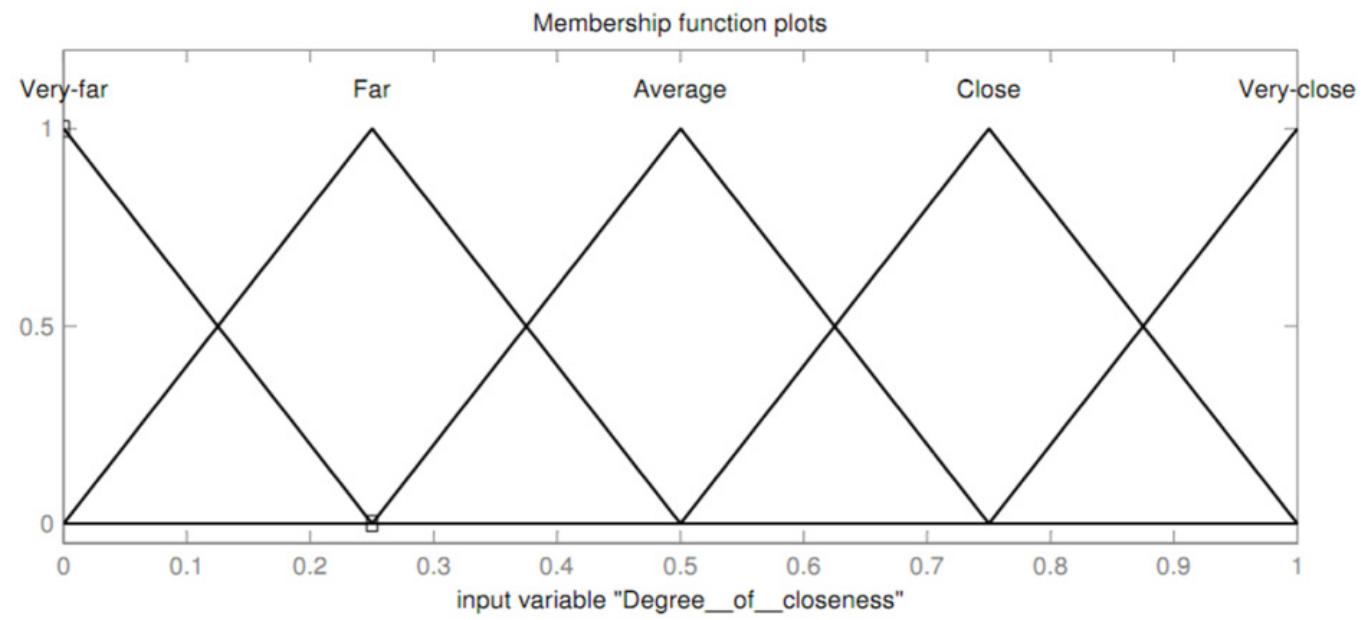

Figure 11. The linguistic terms of Degree of closeness fuzzy input variable and membership function plots (source: self-study)

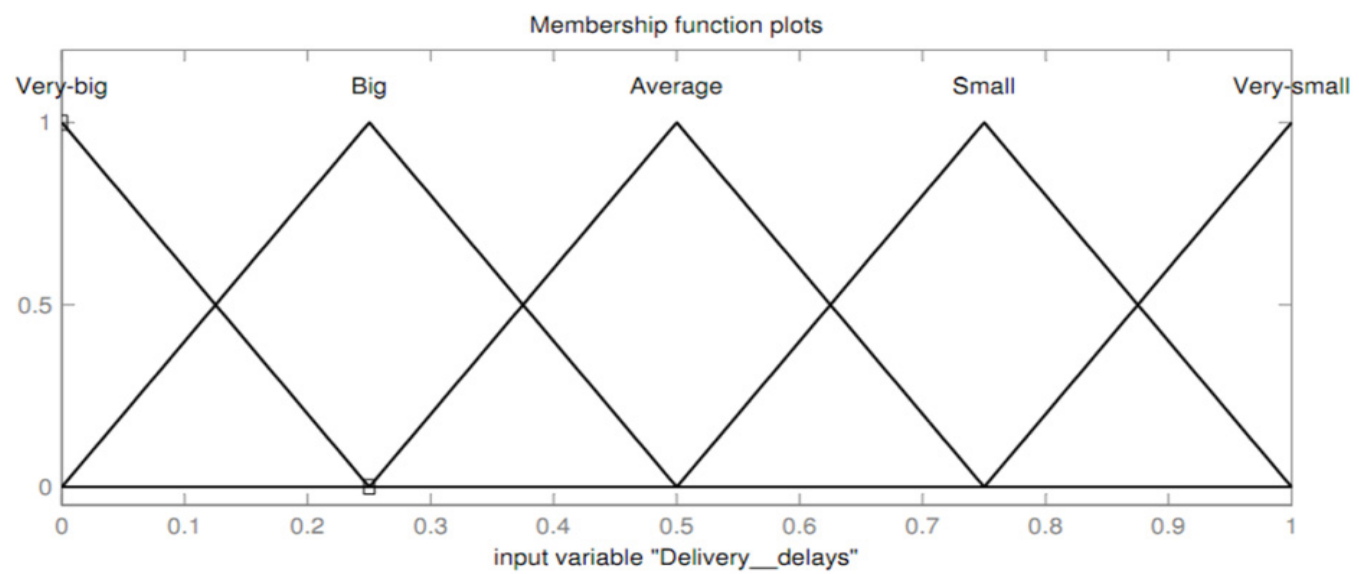

Figure 12. The linguistic terms of Delivery delays fuzzy input variable and membership function plots (source: self-study) 


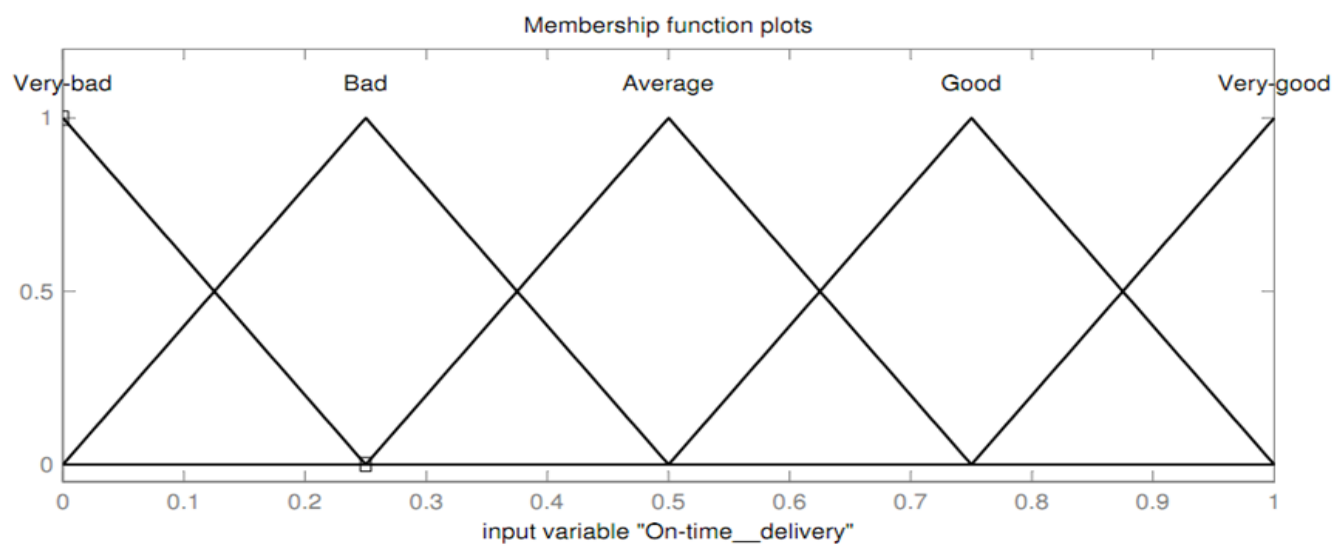

Figure 13. The linguistic terms of On-time fuzzy input variable delivery and membership function plots (source: self-study)

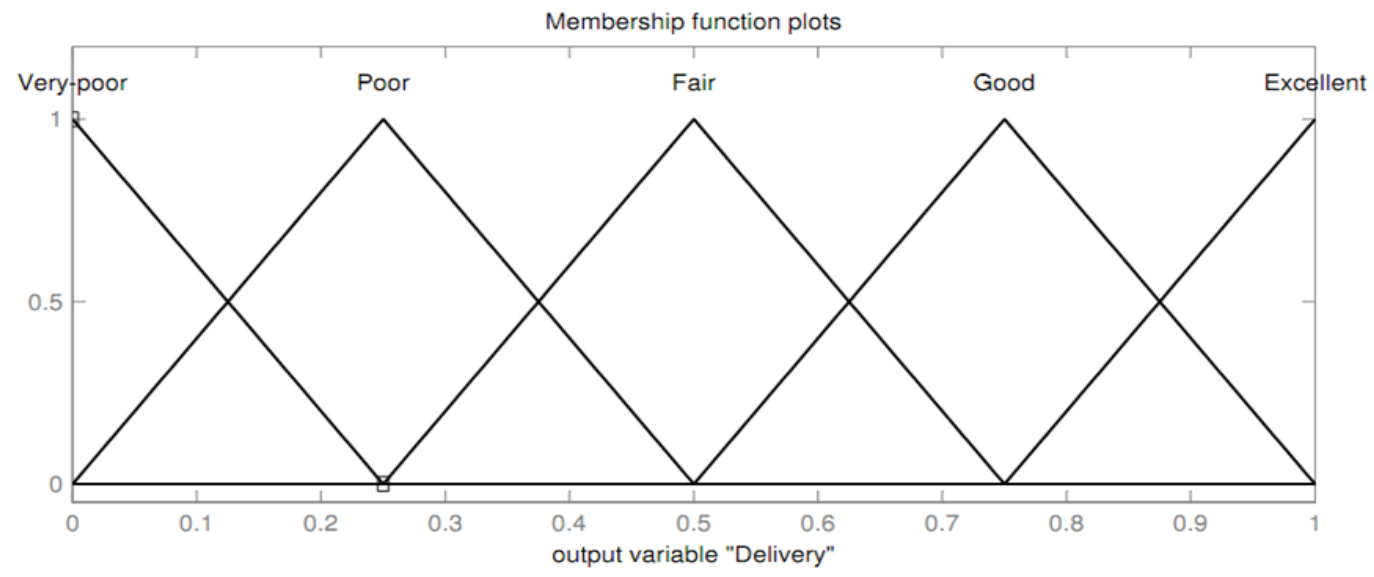

Figure 14. The linguistic terms of Delivery and membership fuzzy output variable function plots (source: self-study)

There are six fuzzification rules which were used in this controller:

1) if (Delivery_condition is Very-bad) or (Degree_of_closeness is Very-far) or (Delivery_delays is Very-big) or (On-time_delivery is Very-bad) then (Delivery is Very-poor),

2) if (Delivery_condition is Bad) or (Degree_of_closeness is Far) or (Delivery_delays is Big) then (Delivery is Poor),

3) if (On-time delivery is Bad) then (Delivery is Poor).

4) if (Delivery delays is Average) or (On-time delivery is Average) then (Delivery is Fair),
5) if (Delivery_condition is Good) or (Degree_of_closeness is Close) or (Delivery_delays is Small) or (On-time_delivery is Good) then (Delivery is Good),

6) if (Delivery_condition is Very-good) or (Degree_of_closeness is Very-close) or (Delivery_delays is Very-small) or (On-time delivery is Very-good) then (Defivery is Excellent).

This controller possesses an additional functionality - it can assign different weights to various fuzzification rules. However, due to the theoretical character of the problem it has been decided that all rules are equivocal. 

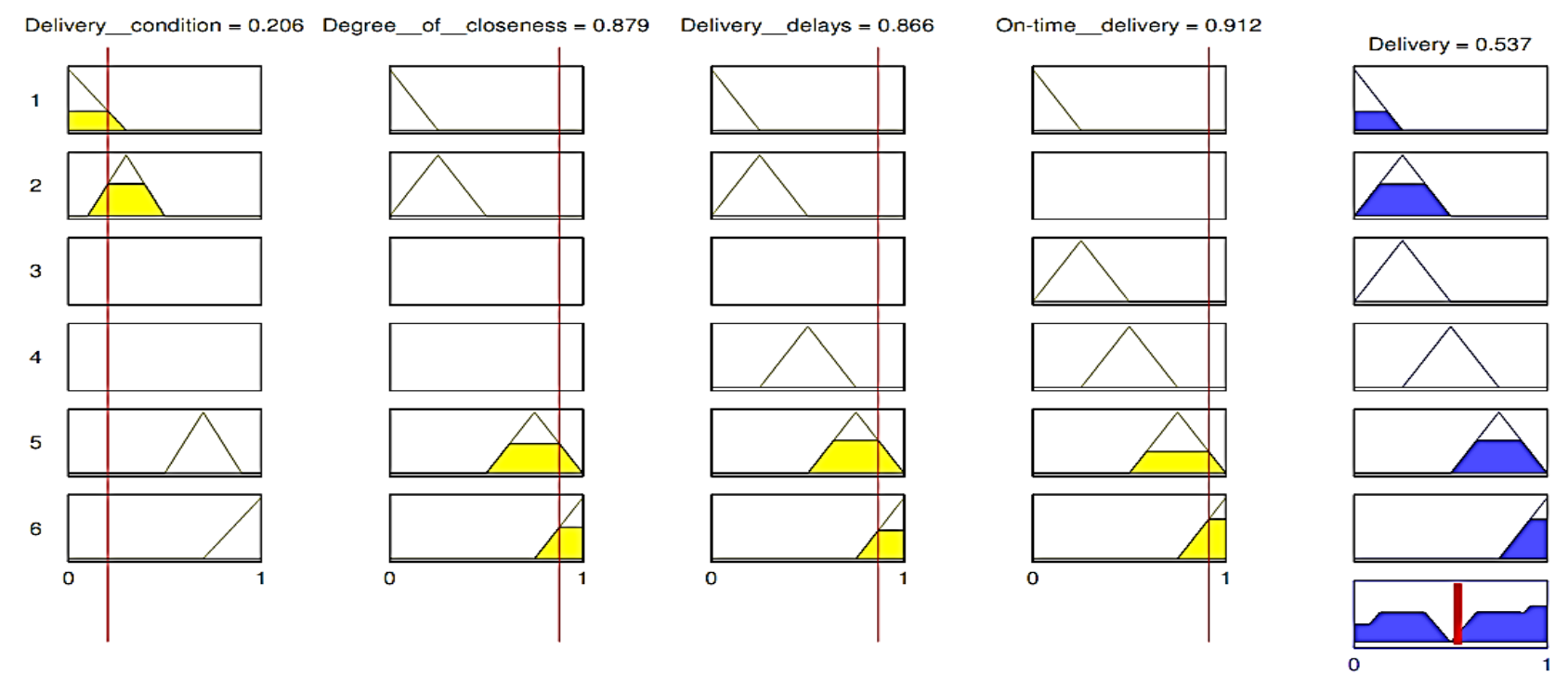

Figure 15. Fuzzy reasoning realized by FIS controller (source: self-study)

The theoretical performance of the controller is illustrated in Fig.15. In the presented scenario, each of the five variables takes different values. The first four columns in Fig. 15 correspond to the four input variables, while the fifth one stands for an output variable. In this case the fuzzy input variables take their values from Table 3.

Table 3 . The values of fuzzy input variables (source: own work)

\begin{tabular}{|l|c|}
\hline \multicolumn{1}{|c|}{ Fuzzy input variable } & Value \\
\hline Delivery conditions & 0,206 \\
\hline Degree of closeness & 0,879 \\
\hline Delivery delays & 0,866 \\
\hline On-timedelivery & 0,912 \\
\hline
\end{tabular}

The first six rows in Figure 15 reflect six rules of fuzzification, whilst the lower right corner presents the process of defuzzification. The graphs in the right column depict the final results of the six rules of fuzzification being applied on the variables. The next stage entails result aggregation for each of the rules which is used to draw an aggregate graph. This graph portrays a substantial form, which constitutes a starting point for the next stage of fuzzy logic control - defuzzification. This process is accomplished with a centroid method, which progresses according to formula 3.

$$
y=\frac{\int \mu_{\widetilde{A}}(x) x d x}{\int \mu_{\widetilde{A}}(x) d x}
$$

Fig. 16 illustrates defuzzification in this method. It can be observed that determining the coordinates of the center of mass of the form is not required, since the final result is read from the horizontalaxis of the figure. In this case the final result equals 0,537 .

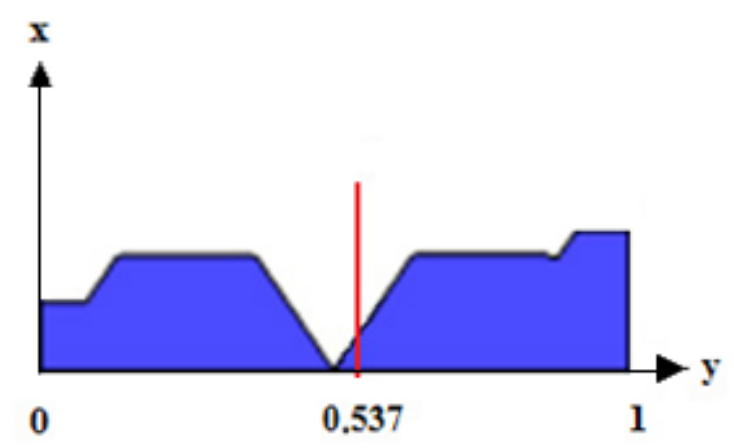

Figure 16. Defuzzification with centroid method (source: self-study)

Fig.17 presents the surface of available solutions, which depicts the values that the output Delivery variable can take depending on the two selected input parameters: Degree_of_closeness and Delivery_conditions. As can be seen the surface presented in the shape is irregular which signifies that the used inference mechanism was very complex. Apart from that it should be noted that Fig. 17 presents merely a fragment of a bigger issue, as the fuzzy controller uses four variables in the evaluation of the quality of the delivery, not just two as in this case. This figure illustrates the fundamental advantage of scalable inference systems based upon fuzzy logic - their efficiency. 


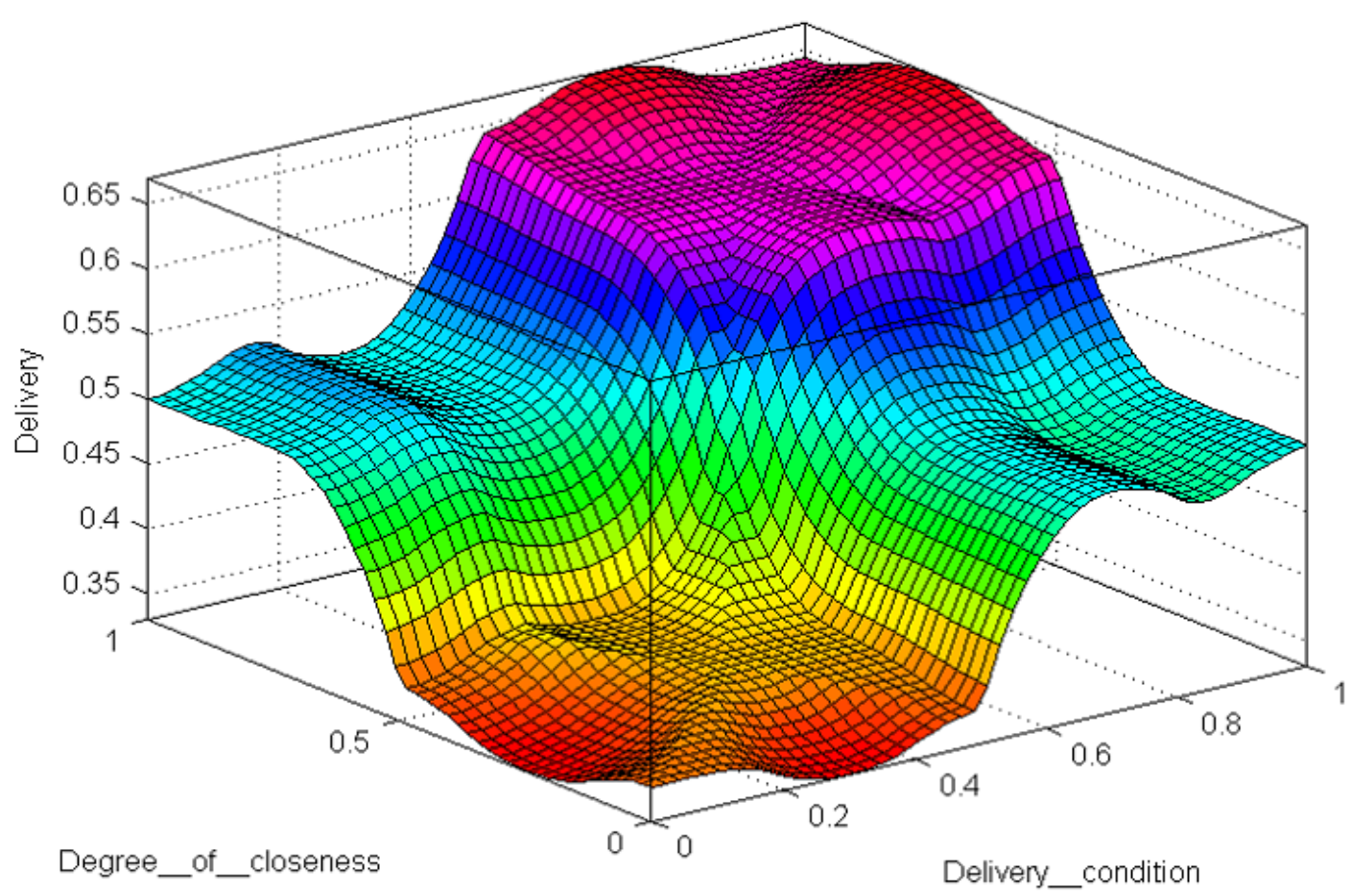

Figure 17. The linguistic terms of fuzzy variable Delivery condition and membership functions plots (source: self-study)

The progress in ICT fields permits a designer to construct a controller with relatively low amount of work using just standard simulation software. This controller can comprise plenty of subtle elements, which reflect even the most mundane aspects of selecting a contractor.

Apart from the fuzzy logic techniques, the problem of multicriterional selection can be addressed using other methods that depend on information technologies, such as: Data Envelopment Analysis (DEA), Analytic Hierarchy Process (AHP) [1], Decision Support System (DSS) based on the AHP model [15], Cluster Analysis (CA) [2], Case Based Reasoning (CBR) [6] etc.

\subsection{Identification of resources and their monitoring}

The method of identifying and monitoring the resources distributed in a cloud environment in real time is another important problem that needs to be dealt with at the stage of designing a cloud manufacturing platform. In order that the process can be performed it is necessary to link all the monitored assets of the enterprise (e.g. CNC machine tools) to a LAN/WAN network. This condition is not difficult to fulfill, especially if the company has $\mathrm{CNC}$ class devices which are less than ten years old. This type of devices is usually fitted with RJ-45 interfaces or WiFi LAN adapters that can be used to connect them to a network. The method of communication of $\mathrm{CNC}$ tool with the entire system is another important question. The communication should be founded on the software that can read the data from $\mathrm{CNC}$ machine tools operator which use different control systems (e.g. Sinumerik, Heidenhain, Fanuc etc.) and transform them to universal format. To this end MTConnect standard, which is a trusted solution based on an open data transfer protocol, can be used [5].

The principal advantage of MTConnect is the capacity to connect every machine tool to a LAN network with plug-and-play technology [30]. This eliminates potential problems with adding and disconnecting new machines in information network. It is important to remember, however, that the straightforwardness of making changes in the machine park makes it difficult to plan the production ahead. This raises the need to use appropriate production planning software. A 14 day advance period appears to be a sensible planning horizon, but its applicability depends on the manufacturing specification of each company. 


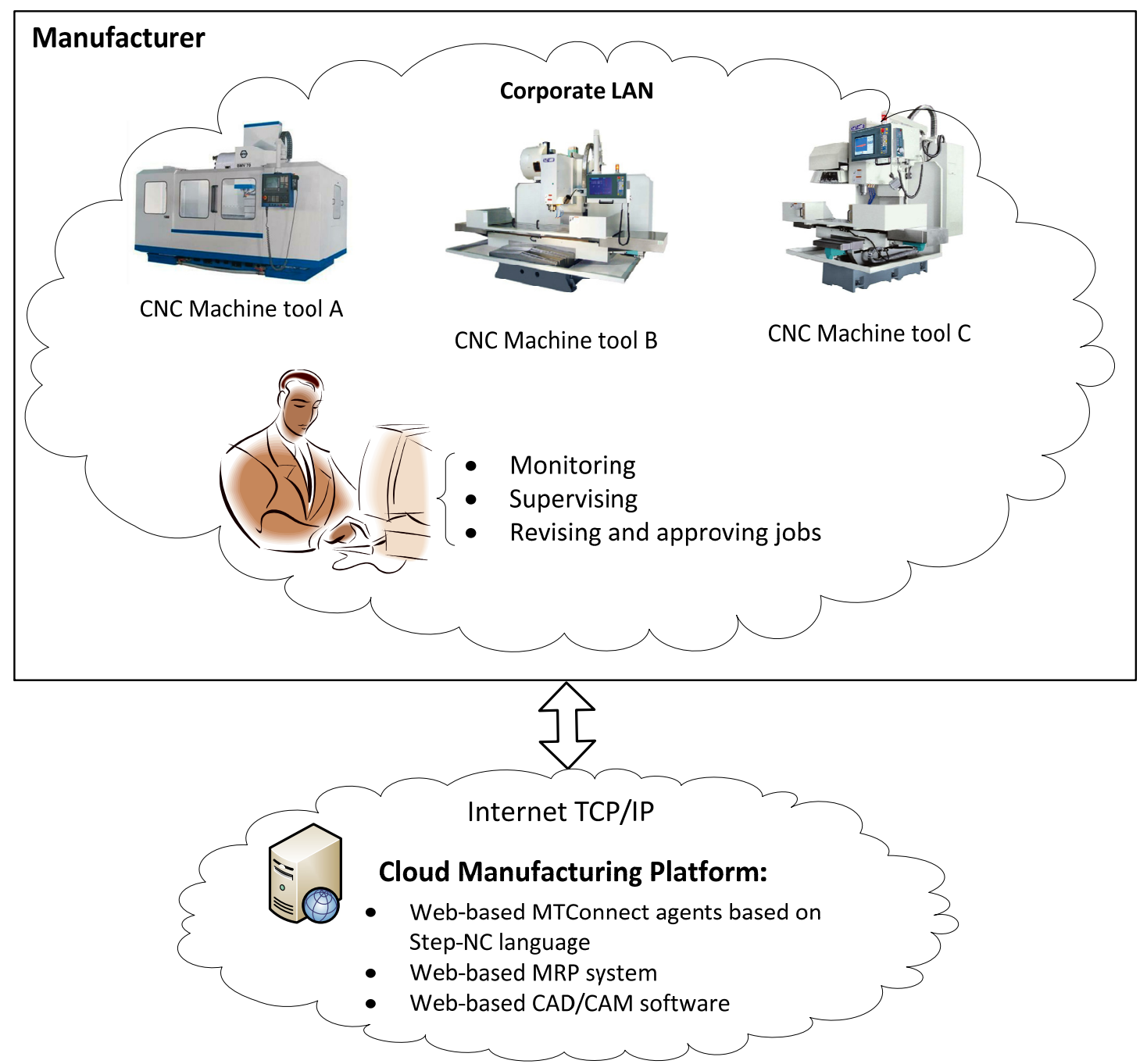

Figure 18. Cloud manufacturing resources and services (source: self study on the basis of [34])

Taking into consideration the capabilities of modern technologies and the complexity of this problem it is premature to assume that all tasks could be automatically (without operator's involvement) directed to individual machines. However, this issue should be properly analyzed and addressed by scientists and engineers in the future. Fig. 18 presents a surveillance diagram of companies associated in a manufacturing cloud with $\mathrm{CNC}$ machines and services implemented through a web portal.

In general, MTConnectstandard is limited to constant surveillance of the assets that belong to a business, but when interfaced with STEP-NC language this standard can also be used to launch discrete manufacturing tasks on individual machine tools ([5], [14], [35] and [36]).

\section{$6 \quad$ Internet of things as a way of multimodal industries integration}

As mentioned before Global Service Layer (see Fig. 4) which belongs to Enterprise domain includes a number of tools that can be used to adapt available software to a cloud. As a consequence all services can be adapted to PaaS delivery model. The success of cloud manufacturing concept depends on three basic factors: calability, flexibility and agility, all of which can be established by virtualization [13]. This raises the need for stable interconnections between physical devices and products. The key to efficient implementation of this task is the concept of Internet of Things which has been defined as "things having identities and virtual personalities operating in smart spaces using intelligent interfaces to connect and communicate within social, environmental, and user contexts" [24]. 


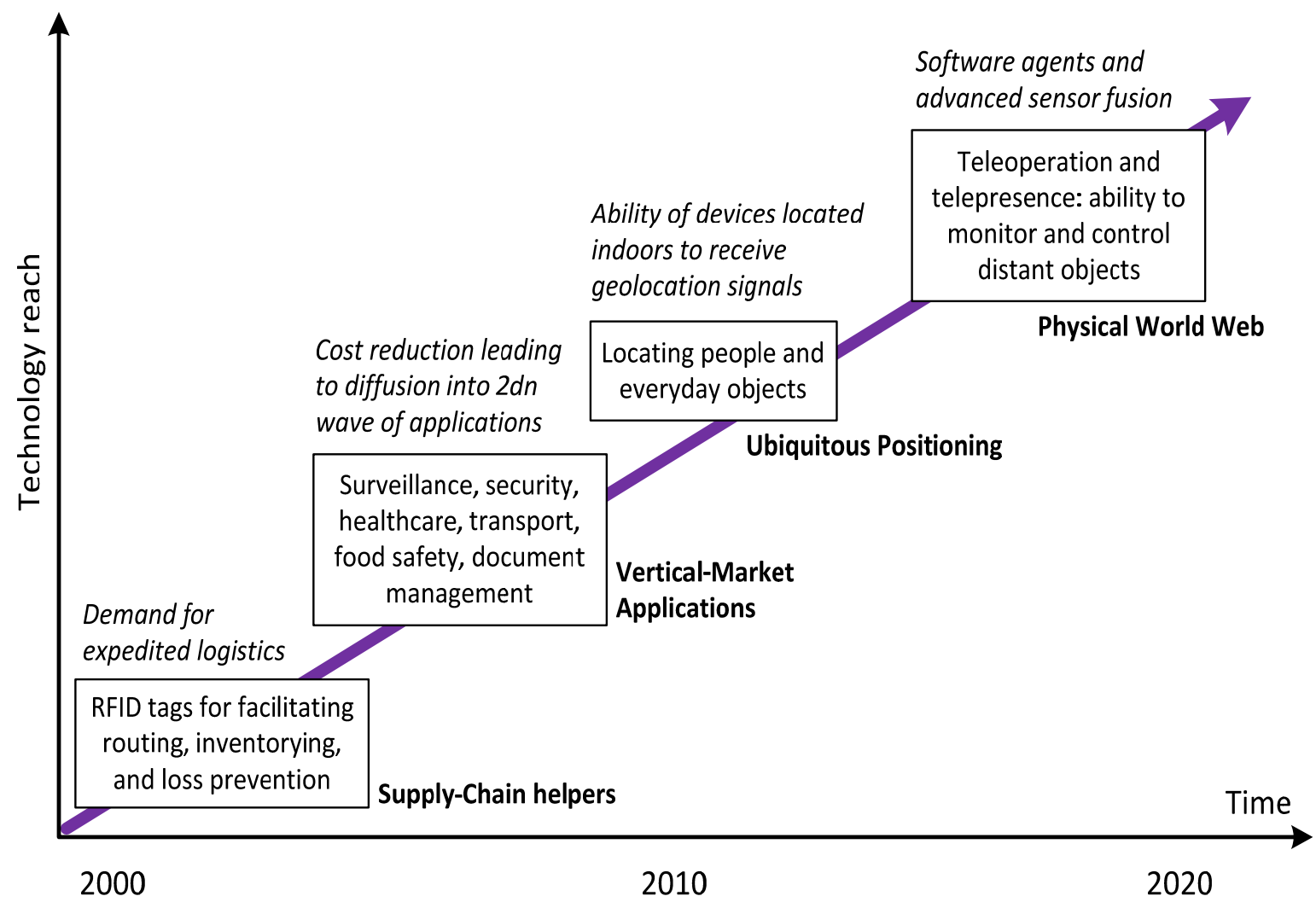

Figure 19. Internet of things - technology roadmap (source: [23])

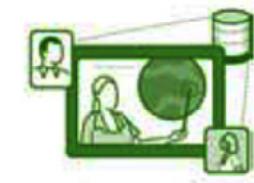

Access to global resources

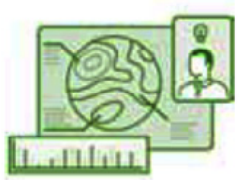

Low cost simulation
Highly interactive/ collaborative learning

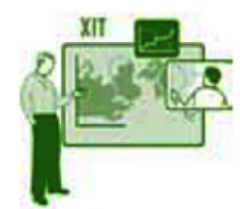

Rapid prototyping \& collaborative design
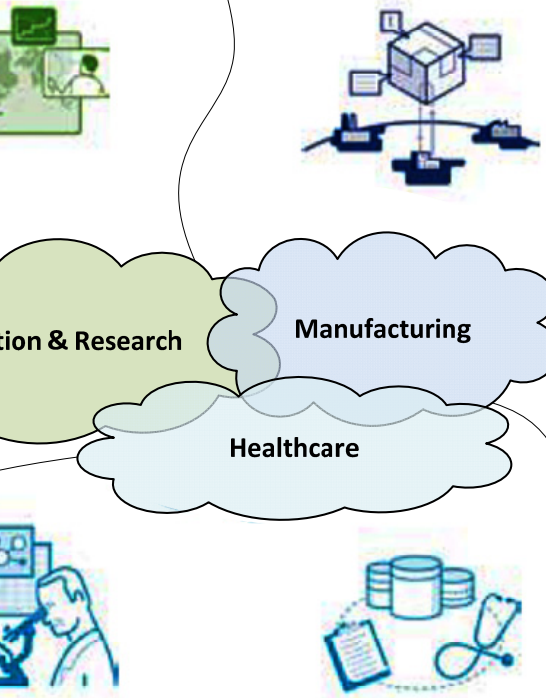

Platform for health

Massive and flexible computing power for drug discovery

and insurance services
Improved manufacturing processes
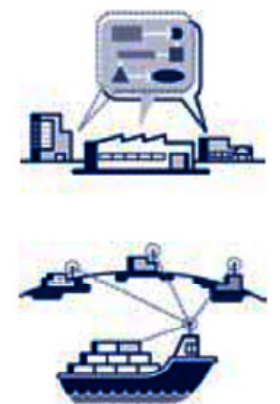

Supply chain coordination

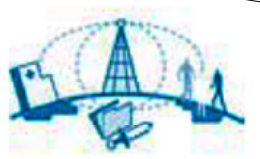

Real-time health monitoring/ alert distribution

Figure 20. Potential use of cloud computing in multimodal industries

(source: [33]) 
The direction of the evolution of Internet of things is presented in Fig. 19. As a result of a rapid technological development the drastic drops of market prices is a common phenomenon which improves the availability of the latest solutions.

The beginning of this century was marked with the invention of RFID (Radio-Frequency Identification) - a technology which, for example, allowed tracking goods in warehouses ([16], [17], [18]). This had a huge impact of logistical processes which fortified logistical branches of business. Further advancements were centered on decreasing the costs connected with making a purchase and implementing the technology that identifies physical resources. This reduction was made possible owing to numerous factors, such as creating application centered around industrial lines of business (e.g. security, healthcare, transport etc.), and the utilization of Electronic Product Code (EPC). The next stage in the evolution of Internet of Things, which we can witness now, is the widespread access to technologies which enable localizing goods and people inside a building. This phenomenon stems from the use of portable devices such as smartphones and Global Positioning Systems (GPS). The last prospective stage in the evolution of Internet of Things is Physical World Web. The attainment of such high technological level is conditioned by widespread (cheap or free) access to wireless Internet connections.

\section{Opportunities for cloud-based integration of multimodal environment}

The adaptation and implementation of cloud manufacturing to the manufacturing field is one of the possible ways to practically utilize the latest IT achievements. The overriding objective of all economic entities is the realization of the rudimentary manufacturing or service processes, and therefore in the enterprises not involved in IT operations directly, information technologies play auxiliary role. At the same time it is easy to observe that the highest dynamics of technological progress takes place in IT industries. In effect there is a significant disproportion between both categories of business. This phenomenon results in the reduction of technological progress on the macro scale. For example, the lack of adaptation in manufacturing sphere may prevent implementing the newest IT advancements. In this scenario, there is a huge potential for the development of the given industrial sphere, although there are still no simple and affordable solutions which would encourage the shift to the new method of providing goods and services. There's an important obstacle which slows down the progress in the automatization of manufacturing process - the multimodal diversity of manufacturing and service systems. The method of diversification is conditioned by assumed division criteria. The organization of manufacturing process defines two categories of production - discrete and process manufacturing. Taking into account business criterion we can distinguish the following manufacturing disciplines: automotive, consumer, electronics, industrial, chemical elements \& allied products etc [27].

Multimodality is not limited to the manufacturing field. Looking at the higher levels of generalization other branches of economy can be observed - ones which just like manufacturing could take advantage of technological diffusion, particularly as far as cloud computing is concerned. Fig. 20 presents the areas that are expected to be affected by the diffusion of cloud computing concepts in the nearest future. Apart from manufacturing there are also three other spheres which are likely to implement cloud computing model - education and research, and healthcare. Within the realm of manufacturing the largest benefits are expected to be gained in rapid prototyping and collaborative design, manufacturing processes and supply chain coordination. Analogically, in the field of education and research the greatest promise of benefits is anticipated in: interactive \& collaborative learning, global resources access, low cost simulation. On the other hand, healthcare has the best prospects in drug discovery, health and insurance services, real-time health monitoring and alert distribution.

\section{$8 \quad$ Cloud operating models}

The multimodality of those economic spheres is a serious barrier on the way to innovate business models with cloud computing solutions. Fig. 21 presents elements that should be integrated in a cloud model: clients, services, applications, infrastructure, platform and storage. The scheme above should be treated universally, which means it is adequate not only in building business models in the manufacturing realm, but also in other business spheres. 


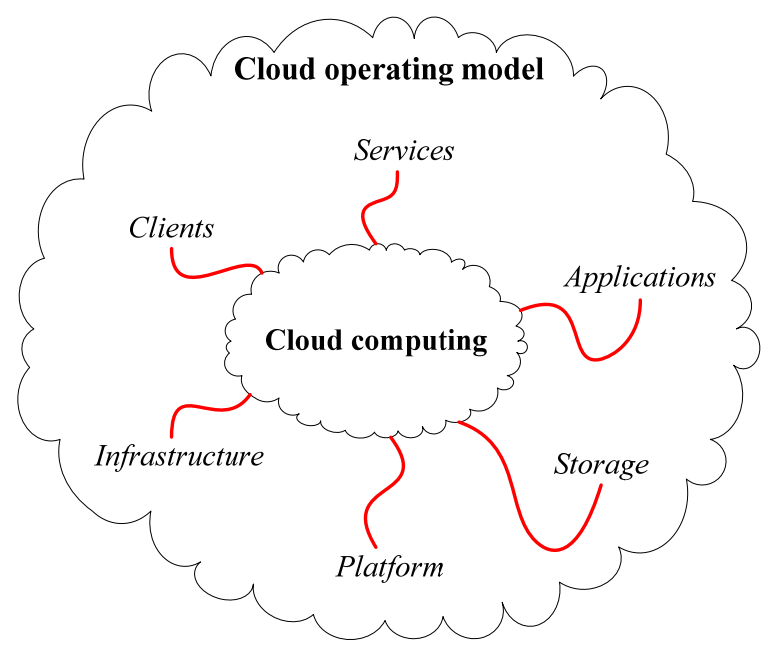

Figure 21. Cloud operating model (source: [32])

The use of cloud computing business model can secure certain tangible benefits (see Fig. 22). Some of the consequences of implementing cloud based solutions can be recognized almost immediately, while others become apparent after some time. The immediate effects include: increase in IT flexibility, improving IT and business process efficiency, reduction IT costs. he mid-term benefits are: a drop in the cost of failure, enhancement of collaboration, facilitation of business agility etc. The long-term macro-scale effects include: accelerated innovation, progress in $\mathrm{R} \& \mathrm{D}$ and science, creation of new jobs and businesses, empower individuals, promotion of sustainability, etc.

Adapting the concept of cloud computing in manufacturing environments grants many benefits which have been enumerated in this article. Those benefits stem from the utilization of the web portal as a platform whose function is to integrate varied cloud manufacturing ideas and elements. Due to the high levels of diversification of business models and operational strategies which are implemented by manufacturing enterprises, there may be the problem with preparing one unified business strategy which would be acceptable to all companies associated in the cloud. As early as during the process of designing MRP/ERP systems which will be offered in SaaS model, one of four possibilities should be taken into consideration [32]:

1) one sizefitsall,

2) a few standard operating models,

3) process-based "a la carte" flexibility,

4) unique operating model for each business model.

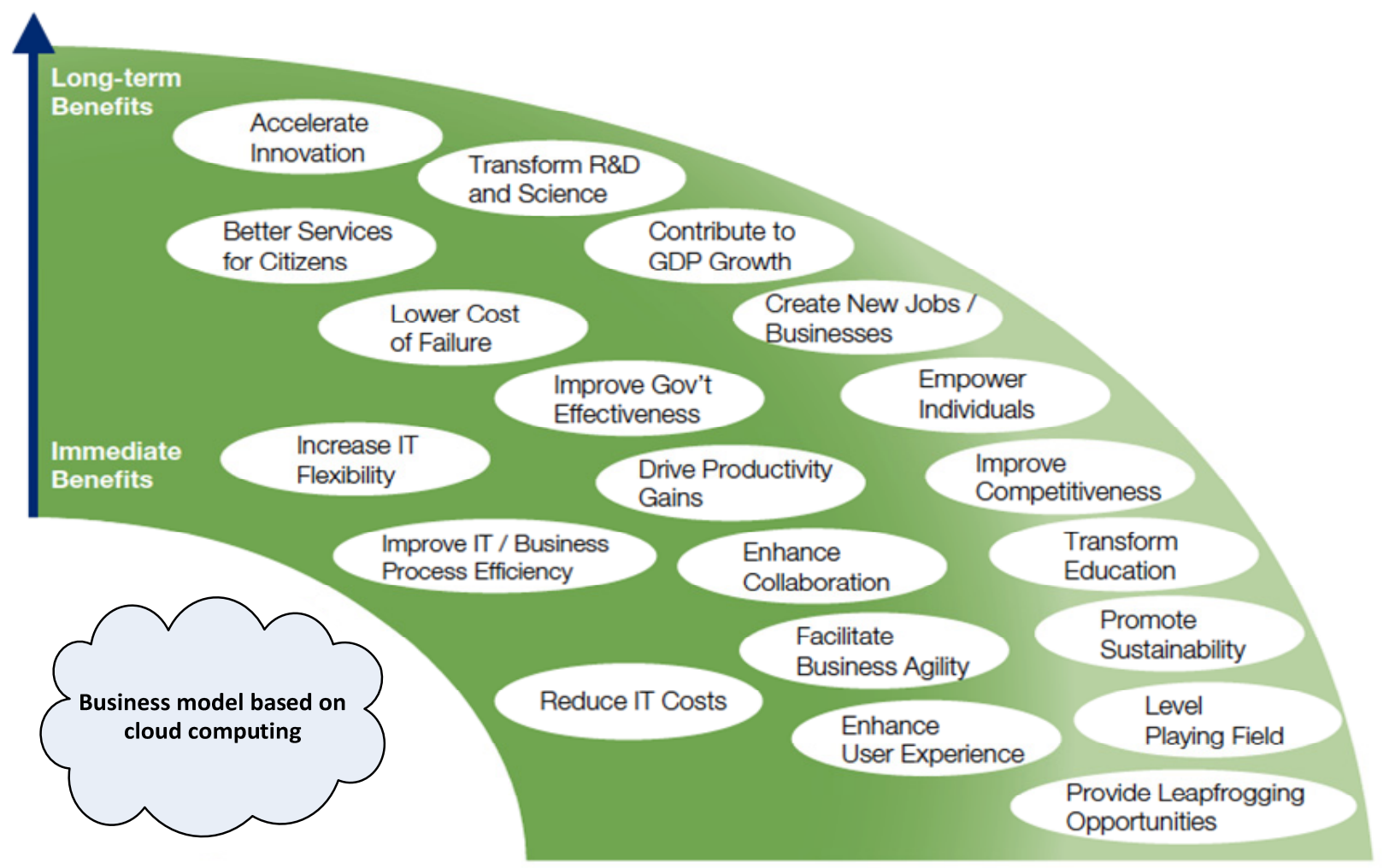

Figure 22. Potential use of cloud computing in multimodal industries (source: [33]) 
The chief advantage of One size fits all model is its simplicity, but many companies wouldn't be able to comply to its cornerstones on account of the specific nature of their ventures. The next operation model a few standard operating model - involves creating two or three separate models, which are a little bit more detailed than their singular counterpart. Depending on enterprise the decision-making mechanism included in one of the services available in a manufacturing cloud would select the best operating model for a concrete manufacturing company.

As a consequence the proposed operating model would fit the enterprise specialty better, but the cost of this solution would higher as it would require preparing separate instances of MRP/ERP software. The third model called Process-based "a la carte" flexibility entails designing integrated business management system that could be characterized by variable processes. In effect, an automated decision making device or a human operator can select the methods of performing individual stages of the business processes form the available options. Assuming that these processes are subdivided into phases and each phase could be realized in two or three ways, this system would enjoy high customizability. The major disadvantage of such system would be the substantial cost of building the required software. The last operating model is unique operating model for each business model. According to its tenets each individual company ought to have its own separate system. From a company's perspective this is the best solution, but it is also the least practical because of the enormous costs of preparing independently working MRP/ERM class systems. Admittedly, those systems could be created in the course of collaboration between multiple designers and integrated into PaaS models which would consist of varied components available in a component cloud in the form of services. Nevertheless, the amount of resources consumed by the entire undertaking most likely would be too high to be acceptable.

\section{Selecting a cloud business model provider}

A practical realization of a web platform based on the concept of cloud manufacturing depends on the choice of appropriate SaaS, PaaS or IaaS solution. These services are usually provided through standardized interfaces such as Web Services, SOA [28] or Representational State Transfer (REST) [7].
Software-as-a-Service model is also sometimes known as AaaS (Application-as-a-Serivce). The term signifies that within the same public computing cloud many clients at once use common resources such as the service offered by an application and databases. For this reason this model is often referred to as Application Service Provider (ASP). There already are many service providers of this kind, the most important of whom are:

- NetSuite, that offers the system including powerful full-featured accounting, CRM, inventory, and ecommerce,

- Google Apps with Capable Online Productivity Suite that offers comprehensive suite of tools, good real-time sharing and collaboration features.

An important factor which reflects the effectiveness of SaaS model is its integration with other application. On this level the most important factors are: scalability, efficiency, accessibility, configurability and resistance to damage.

Platform-as-a-Service model supplies developers with a platform that can host a complete Integrated Development Environment, which can be used to fulfill the entire software release life-cycle. We discriminate the following stages of the life-cycle: development, testing, implementation and hosting of the advanced web application. All of the functionalities are services provided in a cloud. There are a number of integrated PaaS solutions available: Amazon EC2, Google App Engine, Netsuite, Daptiv, Bungee Labs, Coghead, Heroku, Rollbase, Microsoft Windows Azure and more. A PaaS platform offers a wide range of easily accessed services, which means that it can service multiple applications within the same platform.

Infrastructure-as-a-Service (IaaS) model is also sometimes referred to as Hardware as a Service (HaaS). IaaS constitutes a certain payment model for using this technology which relies on the frequency of the use of the equipment. This service is in particular convenient to corporate users, since it eliminates the need to invest in establishing and managing their own IT systems. The constant access to the latest software is a significant advantage of IaaS models. The company that employs this solution does not have to take care of technical details of IT structures they are using, which allows them to concentrate of their fundamental activities and making profit.

Table 4 presents a simple comparison of eleven selected IaaScloud computing technology providers [29]. 
The names of providers are placed in the table columns. The comparison of the providers was based on the following fifteen criteria:

1) Pricing Plan - this criterion is treated as better when more options is provided, but the pay-asyou-go model is the most wanted stand-alone option, because it allows the best usage control.

2) Average Monthly Price - this criterion reflects estimated cost (in USD) for a $1 \mathrm{CPU}$ and $2 \mathrm{~GB}$ RAM in cloud server. The value was averaged over datacenters for companies with locationbased pricing, and averaged over Windows/Linux servers. When available, hourly pricing was used with assumption that one month includes 730 hours. Otherwise, monthly pricing was used. Data transfer costs are omitted.

3) Service Level Agreement (SLA) - this criterion reflects the proportionate uptime SLA.

4) Number of Datacenters - this criterion describes the number of available datacenters when cloud servers are deployed.

5) Certifications - this Boolean type criterion reflects compliance and security-related certifications (e.g. PCI or SAS 70).

6) Scale Up - this Boolean type criterion reflects possibility of scaling up individual cloud server instances by adding e.g. more memory, extra CPUs, more storage space etc.

7) Scale Out - this Boolean type criterion describes possibility of quick deploying new server instances.

8) Support - this is the three-level criterion:

a) poor - encompasses providers that the free offer includes on-line forums only but any other support must be paid,

b) average - encompasses providers that offer an extra free support (via phone or on-line chat), apart from forums,

c) extensive - encompasses providers in which the base price covers multiple support offerings.

9) Monitoring - this criterion is 3-level scaled:

a) poor - including providers with no monitoring and alert solutions, requiring the thirdparty tools deployment or there is the need to use of extra services, b) average - including providers with very simple integrated monitoring tools (not much indicators, no alerting),

c) extensive - encompasses providers with fully integrated monitoring tools that are included in price.

10) APIs - this 3-stage criterion (None, Average, Extensive) describes the level of offering of Application Programming Interfaces to interact with the servers.

11) Free Tier - this Boolean type criterion is set "Yes" when the provider allows "free trial" tier that customers can use to test the service.

12) Supported operating systems (SOS) - this criterion reflects the number of supported operating systems.

13) Number of Instance Types - this criterion reflects the available number of different server configurations. "Configurable", means that provider offers fully customizable server.

14) Transfer Cost-out - cost of outbound data transfer calculated in USD for each GB of outbound data sent from the server. Zero means that given provider offers a "per second" (Mbps) connection for free.

15) Transfer Cost-in - cost of inbound data transfer calculated the same way as above.

Table 4 was divided into two parts. The information in the upper part concerns individual service providers and criteria. The data from the upper segment of the table are qualitative and quantitative in character. The lower part of the table contains the ranking of service providers that came about as a result of transforming descriptive information into actual figures.

The higher the numbers for the higher position in the ranking. The maximal value of each criterion is 1 ; the minimal equals 0 . Formula 4 was used to calculate the final score for each provider.

$$
\mathrm{S}_{\mathrm{j}}=\mathrm{N}^{-1} \sum_{\mathrm{i}=1}^{\mathrm{N}} \mathrm{c}_{\mathrm{ij}} \mathrm{w}_{\mathrm{i}}
$$

where: $S_{j}-$ final score of provider $\mathrm{j}, \mathrm{N}-$ number of criteria (in this case $\mathrm{N}=15$ ), $\mathrm{c}_{\mathrm{ij}}$ - value of criterion i for provider $\mathrm{j}, \mathrm{w}_{\mathrm{i}}-$ weight of criterion $\mathrm{i}$ (in this case $\left.\mathrm{w}_{1 . \mathrm{N}}=1\right)$. 
Table 4 . Comparison of different IaaS providers (source: self-study on the basis of [29])

\begin{tabular}{|c|c|c|c|c|c|c|c|c|c|c|c|c|}
\hline \multicolumn{2}{|c|}{$\begin{array}{l}\text { Provider } \\
\text { Criterion }\end{array}$} & \multirow{2}{*}{$\begin{array}{c}\text { Amazon } \\
\text { EC2 } \\
\text { Pay-as- } \\
\text { you-go or } \\
\text { Year }+ \\
\text { Discount }\end{array}$} & \multirow{2}{*}{$\begin{array}{c}\begin{array}{c}\text { Bit } \\
\text { Refinery }\end{array} \\
\text { Monthly }\end{array}$} & \multirow{2}{*}{$\begin{array}{c}\text { Go- } \\
\text { Daddy } \\
\text { Monthly }\end{array}$} & \multirow{2}{*}{$\begin{array}{l}\text { GoGrid } \\
\text { Pay-as- } \\
\text { you-go } \\
\text { or } \\
\text { Monthly }\end{array}$} & \multirow{2}{*}{$\begin{array}{c}\text { Host- } \\
\text { ing.com } \\
\text { Monthly }\end{array}$} & \multirow{2}{*}{$\begin{array}{l}\text { Nepho- } \\
\text { Scale } \\
\text { Pay-as- } \\
\text { you-go or } \\
\text { Year + } \\
\text { Discount }\end{array}$} & \multirow{2}{*}{$\begin{array}{c}\text { Op- } \\
\text { Source } \\
\text { Pay-as- } \\
\text { you-go or } \\
\text { Monthly }\end{array}$} & \multirow{2}{*}{$\begin{array}{l}\text { Rack- } \\
\text { space } \\
\text { Pay-as- } \\
\text { you-go }\end{array}$} & \multirow{2}{*}{$\begin{array}{l}\begin{array}{l}\text { Relia- } \\
\text { Cloud }\end{array} \\
\text { Monthly }\end{array}$} & \multirow{2}{*}{$\begin{array}{c}\begin{array}{c}\text { Soft- } \\
\text { layer }\end{array} \\
\text { Pay-as- } \\
\text { you-go } \\
\text { or } \\
\text { Monthly }\end{array}$} & \multirow{2}{*}{$\begin{array}{c}\text { Terre- } \\
\text { mark }\end{array}$} \\
\hline Pricing & 1 & & & & & & & & & & & \\
\hline $\begin{array}{l}\text { Average } \\
\text { Price / } \\
\text { Month } \\
\text { (US\$) }\end{array}$ & 2 & 80,81 & 137 & 39,99 & 273,6 & 270 & 146 & 87,6 & 51,1 & 135,05 & 135,05 & 133,39 \\
\hline SLA & 3 & $99,95 \%$ & $100 \%$ & $99,90 \%$ & $100 \%$ & $100 \%$ & $99,95 \%$ & $100 \%$ & $100 \%$ & $100 \%$ & $?$ & $100 \%$ \\
\hline $\begin{array}{c}\text { Datacen- } \\
\text { ters }\end{array}$ & 4 & 7 & 1 & 8 & 2 & 4 & 1 & 4 & 9 & 2 & 7 & 9 \\
\hline $\begin{array}{l}\text { Certifica- } \\
\text { tions }\end{array}$ & 5 & Yes & Yes & No & No & Yes & No & Yes & Yes & Yes & Yes & Yes \\
\hline Scale Up & 6 & No & Yes & No & Yes & Yes & Yes & Yes & Yes & No & No & Yes \\
\hline Scale Out & 7 & Yes & Yes & Yes & Yes & Yes & Yes & Yes & Yes & Yes & Yes & Yes \\
\hline Support & 8 & Poor & Extensive & $\begin{array}{l}\text { Exten- } \\
\text { sive }\end{array}$ & $\begin{array}{l}\text { Exten- } \\
\text { sive }\end{array}$ & Extensive & Average & Extensive & $\begin{array}{l}\text { Exten- } \\
\text { sive }\end{array}$ & Average & Poor & Poor \\
\hline $\begin{array}{l}\text { Monitor- } \\
\text { ing }\end{array}$ & 9 & Extensive & Poor & Poor & Poor & Average & Poor & Average & $\begin{array}{l}\text { Exten- } \\
\text { sive }\end{array}$ & Poor & $\begin{array}{l}\text { Exten- } \\
\text { sive }\end{array}$ & Poor \\
\hline APIs & 10 & Extensive & None & None & Average & None & Extensive & Extensive & $\begin{array}{l}\text { Exten- } \\
\text { sive }\end{array}$ & Average & $\begin{array}{l}\text { Exten- } \\
\text { sive }\end{array}$ & Average \\
\hline Free Tier & 11 & Yes & No & No & No & No & Yes & No & No & No & No & No \\
\hline SOS & 12 & 9 & 3 & 4 & 4 & 3 & 4 & 4 & 8 & 5 & 6 & 5 \\
\hline $\begin{array}{c}\text { Instance } \\
\text { Types }\end{array}$ & 13 & 12 & $\begin{array}{l}\text { Configu- } \\
\text { rable }\end{array}$ & 5 & 1 & $\begin{array}{c}\text { Configu- } \\
\text { rable }\end{array}$ & 6 & $\begin{array}{l}\text { Configu- } \\
\text { rable }\end{array}$ & 8 & 5 & 13 & $\begin{array}{c}\text { Configu- } \\
\text { rable }\end{array}$ \\
\hline $\begin{array}{c}\text { Transfer } \\
\text { Cost - out } \\
(/ \mathrm{GB})\end{array}$ & 14 & 0,12 & 0 & 0 & 0,29 & 0 & 0,13 & 0,15 & 0,18 & 0,12 & 0,1 & 0,17 \\
\hline \multirow[t]{2}{*}{$\begin{array}{c}\text { Transfer } \\
\text { Cost - in } \\
(/ \mathrm{GB})\end{array}$} & 15 & 0 & 0 & 0 & 0 & 0 & 0 & 0 & 0 & 0 & 0 & 0,17 \\
\hline & \multicolumn{12}{|c|}{ Scoring } \\
\hline Pricing & 1 & 0,60 & - & - & 1,00 & - & 0,60 & 1,00 & 0,30 & - & 1,00 & 0,30 \\
\hline $\begin{array}{l}\text { Average } \\
\text { Price / } \\
\text { Month } \\
\text { (US\$) }\end{array}$ & 2 & 0,70 & 0,50 & 0,85 & - & 0,01 & 0,47 & 0,68 & 0,81 & 0,51 & 0,51 & 0,51 \\
\hline SLA & 3 & 0,75 & 1,00 & 0,50 & 1,00 & 1,00 & 0,75 & 1,00 & 1,00 & 1,00 & - & 1,00 \\
\hline $\begin{array}{c}\text { Datacen- } \\
\text { ters }\end{array}$ & 4 & 0,78 & 0,11 & 0,89 & 0,22 & 0,44 & 0,11 & 0,44 & 1,00 & 0,22 & 0,78 & 1,00 \\
\hline $\begin{array}{l}\text { Certifica- } \\
\text { tions }\end{array}$ & 5 & 1,00 & 1,00 & - & - & 1,00 & - & 1,00 & 1,00 & 1,00 & 1,00 & 1,00 \\
\hline Scale Up & 6 & - & 1,00 & - & 1,00 & 1,00 & 1,00 & 1,00 & 1,00 & - & - & 1,00 \\
\hline Scale Out & 7 & 1,00 & 1,00 & 1,00 & 1,00 & 1,00 & 1,00 & 1,00 & 1,00 & 1,00 & 1,00 & 1,00 \\
\hline Support & 8 & - & 1,00 & 1,00 & 1,00 & 1,00 & 0,50 & 1,00 & 1,00 & 0,50 & - & - \\
\hline $\begin{array}{c}\text { Monitor- } \\
\text { ing }\end{array}$ & 9 & 1,00 & - & - & - & 0,50 & - & 0,50 & 1,00 & - & 1,00 & - \\
\hline APIs & 10 & 1,00 & - & - & 1,00 & - & 1,00 & 1,00 & 1,00 & 1,00 & 1,00 & 1,00 \\
\hline Free Tier & 11 & 1,00 & - & - & - & - & 1,00 & - & - & - & - & - \\
\hline SOS & 12 & 1,00 & 0,33 & 0,44 & 0,44 & 0,33 & 0,44 & 0,44 & 0,89 & 0,56 & 0,67 & 0,56 \\
\hline $\begin{array}{c}\text { Instance } \\
\text { Types }\end{array}$ & 13 & 0,46 & 1,00 & 0,19 & 0,04 & 1,00 & 0,23 & 1,00 & 0,31 & 0,19 & 0,50 & 1,00 \\
\hline $\begin{array}{c}\text { Transfer } \\
\text { Cost - out } \\
(/ \mathrm{GB})\end{array}$ & 14 & 0,59 & 1,00 & 1,00 & - & 1,00 & 0,55 & 0,48 & 0,38 & 0,59 & 0,66 & 0,41 \\
\hline $\begin{array}{c}\text { Transfer } \\
\text { Cost - in } \\
(/ \mathrm{GB})\end{array}$ & 15 & 1,00 & 1,00 & 1,00 & 1,00 & 1,00 & 1,00 & 1,00 & 1,00 & 1,00 & 1,00 & - \\
\hline Final Sco & & 0,73 & 0,60 & 0,46 & 0,51 & 0,62 & 0,58 & 0,77 & 0,78 & 0,50 & 0,61 & 0,59 \\
\hline
\end{tabular}


In the analyzed scenario it was assumed that the weights of all criteria are equal. The winner of the ranking was Rackspace with the final score of 0,78 .

\section{Conclusions}

The article touched upon the novel concept of cloud manufacturing - an idea heavily grounded in cloud computing model. At the beginning the paper explained three different business models - SaaS, PaaS and IaaS, which operate within cloud manufacturing frameworks. Next it highlighted rudimentary requirements that need to be fulfilled in order to open a web portal, which could aid manufacturing processes. Cloud manufacturing relies on high level of process automatization concerning manufacturing orders, developing technology, machine and contractor selection as well as appraisal and offering. The article discussed many aspects of cloud manufacturing system architecture and identified key obstacles that may make the process of commercialization of this innovative solution more difficult. It also concentrated on the question of matching different machines to different manufacturing orders. The paper analyzed possible solutions to this challenge: using a tested algorithm or taking advantage of classic fuzzy interface system (FIS) which would perform multicriterional selection tasks. It showed how simultaneous progress in related information technologies (e.g. Internet of Things) can improve the performance of cloud computing. The next part of the article dealt with promising segments of economy that potentially can bring profits, and that can be developed only with cloud technologies in use. The paper presented multiple operating models, according to which the manufacturing processes can be organized.

This ranking can be referenced when deciding between SaaS, PaaS or IaaS service providers. Cloud manufacturing is currently in the infant stages of development. At present there are no commercial solutions of this type, although pilot system are being created - ones which realize the chosen tasks characteristic to cloud manufacturing. In multimodal economic, administrative and social environments this translates into full automatization of manufacturing processes. It appears that however distant this strategic objective is, it will constitute a goalpost for many researches in the next few years to come.

\section{References}

[1] Akarte M.M., et al. - Web Based Casting Supplier Evaluation Using Analytical Hierarchy Process [in] Journal of the Operational Research Society, Vol. 52(5), 2001, pp. 511-522.

[2] Bottani E., Rizzi A. - An Adapted Multi-Criteria Approach to Suppliers and Products Selection an Application Oriented to Lead-Time Reduction [in] International Journal of Production Economics, Vol. 111(2), 2008, pp. 763-781.

[3] Bughin J., Chui M., Manyika J. - Clouds, Big Data, and Smart Assets: Ten Tech-Enabled Business Trends to Watch [in] McKinsey Quarterly, McKinsey Global Institute, August 2010.

[4] Buyyaa R., Yeoa C.S., Venugopala S., Broberg J., Brandic I. - Cloud Computing and Emerging IT Platforms: Vision, Hype, and Reality for Delivering Computing as the 5th Utility [in] Future Generation Computer Systems, Vol. 25, 2009, pp. 599616.

[5] Campos J.G., Miguez L.R. - Standard Process Monitoring and Traceability Programming in Collaborative CAD/CAM/CNC Manufacturing Scenarios [in] Computers in Industry, Vol. 62, Issue 3, April 2011, pp. 311-322.

[6] Choy K.L., Lee W.B. - A Generic Tool for the Selection and Management of Supplier Relationships in an Outsourced Manufacturing Environment: the Application of Case Based Reasoning [in] Logistic Information Management, Vol. 15(4), 2002, pp. 235-253.

[7] Fielding R.T. - PhD dissertation: Architectural Styles and the Design of Network-based Software Architectures, Irvine: Department of Information and Computer Science, University of California, http://www.ics.uci.edu/ fielding/pubs/dissertation/t op.htm (accessed: 10.07.2012).

[8] Foster I., Zhao Y., Raicu I., Lu S. - Cloud Computing and Grid Computing 360-Degree Compared [at] Grid Computing Environments Workshop, Chicago 2008, pp. 1-10.

[9] Gola A., Świć A. - Brief Preliminary Design for a Method of FMS Machine Tools Subsystem Selection [in] Proceedings in Applied Mathematics and Mechanics, Vol. 9, 2010, pp. 663-664.

[10] Gola A., Świć A. - Computer-Aided Machine Tool Selection for Focused Flexibility Manufacturing Systems Using Economical Criteria [in] Actual 
Problems of Economics, Vol. 10(124), 2011, pp. 383-389.

[11] Gola A., Świć A. - Elements of Design of Production Systems - Methodology of Machine Tool Selection in Casing-Class FMS [in] Management and Production Engineering Review, Vol. 1, 2010, pp. 73-81.

[12] Gola A., Świć A., Kramar V. - A Multiple-Criteria Approach to Machine-Tool Selection for Focused Flexibility Manufacturing Systems [in] Management and Production Engineering Review, Vol. 2(4), 2011, pp. 21-32.

[13] Golden B. - Virtualization for Dummies, Wiley Publishing, Inc., Indianapolis 2008.

[14] Hardwick M., Loffredo D. - Lessons Learned Implementing STEP-NC AP-238 [in] International Journal of Computer Integrated Manufacturing, Vol. 19(6), 2006, pp. 523-532.

[15] Hou J., Su D. - EJB-MVC Oriented Supplier Selection System for Mass Customization [in] Journal of Manufacturing Technology Management, Vol. 18(1), 2007, pp. 54-71.

[16] Huang G.Q., Wright P.K., Newman S.T. - Wireless Manufacturing: a Literature Review, Recent Developments and Case Studies [in] International Journal of Computer Integrated Manufacturing, Vol. 22(7), 2009, pp. 1-16.

[17] Huang G.Q., Zhang Y.F., Jiang P.Y. - RFID-Based Wireless Manufacturing for Walking - Worker Assembly Islands with Fixed-Position Layouts [in] International Journal of Robotics and Computer Integrated Manufacture, Vol. 23(4), 2007, pp. 469477.

[18] Huang G.Q., Zhang Y.F., Jiang P.Y. - RFID-Based Wireless Manufacturing for Real-Time Management of Job Shop WIP Inventories [in] International Journal of Advanced Manufacturing Technology, Vol. 7-8(36), 2007, pp. 752-64.

[19] Khaleiea S., Fasangharia M., Tavassolib E. - Supplier Selection Using a Novel Intuitionist Fuzzy Clustering Approach [in] Applied Soft Computing, Vol. 12, 2012, pp. 1741-1754.

[20] Li B-H., Zhang L., Wang S-L., Tao F., Cao J-W., Jiang X-D., Song X., Chai X-D. - Cloud Manufacturing: a New Service-Oriented Networked Manufacturing Model [in] Computer Integrated Manufacturing Systems CIMS, Vol. 16(1), 2010, pp. 1-7.
[21] Mell P., Grance T. - Perspectives on Cloud Computing and Standards, National Institute of Standards and Technology (NIST). Information Technology Laboratory, 2009.

[22] Palanivel K., Sivakumar R. - Fuzzy Multicriteria Decision-Making Approach for Collaborative Recommender Systems [in] International Journal of Computer Theory and Engineering, Vol. 2(1), 2010, pp. 57-63,

http://www.ijcte.org/papers/117-G607.pdf (accessed: 10.07.2012).

[23] Report: Disruptive Civil Technologies, Six Technologies with Potential Impacts on US, Interests out to 2025, Appendix f: the internet of things (background),

http://www.dni.gov/nic/PDF_GIF_confreports/disr uptivetech/appendix_F.pdf

(accessed: 10.07.2012).

[24] Report: Internet of Things in 2020 - A Roadmap for the Future, Information Society and Media Directorate-General of the European Commission (DG INFSO) and the European Technology Platform on Smart Systems Integration (EPoSS), 05 September, 2008,

$\mathrm{ftp}: / / \mathrm{ftp} . c o r d i s . e u r o p a . e u / p u b / f p 7 / i c t / d o c s / e n e t / i n t e$ rnet-of-things-in-2020-ec-eposs-workshop-report2008-v3_en.pdf (accessed: 10.07.2012).

[25] Rimal B.P., Jukan A., Katsaros D., Goeleven Y. Architectural Requirements for Cloud Computing Systems: an Enterprise Cloud Approach [in] Journal of Grid Computing, Vol. 9(1), 2011, pp. 3-26.

[26] Shalini S. - Smart Manufacturing with Cloud Computing,

http://www.sramanamitra.com/2010/12/03/smartmanufacturing-with-cloud-computing-part-1/ (accessed: 10.07.2012).

[27] The American Chamber of Commerce in Thailand, Directory-List All Industry Types,

https://www.amchamthailand.com/ACCT/asp/corpl ist_types.asp?SponsorID $=298$ (accessed: 10.07.2012).

[28] The Open Group, Service Oriented Architecture (SOA), http://www.opengroup.org/projects/soa/ (accessed: 10.07.2012).

[29] Thoran R. - The Enterprise Cloud - 11 cloud IaaS Providers Compared, January 24, 2012, http://www.techrepublic.com/blog/datacenter/11cloud-iaas-providers-compared/5285 (accessed: 10.07.2012). 
[30] Van de Velde P.J.M.C. - Runtime Configurable Systems for Computational Fluid Dynamics Simulations [in] PhD thesis. Auckland: Department of Mechanical Engineering, University of Auckland, 2009.

[31] Villegasa D., Bobroffc N., Roderob I., Delgadoa J., Liuc Y., Devarakondab A., Fongc L., Sadjadia S.M., Parasharb M. - Cloud Federation in a Layered Service Model [in] Journal of Computer and System Sciences, Volume 78, Issue 5, September 2012, pp. 1330-1344.

[32] Where the Cloud Meets Reality: Operationally Enabling the Growth of New Business Models, http://www.accenture.com/us-en/pages/insightcloud-enabling-growth-new-business.aspx (accessed: 10.07.2012).

[33] World Economic Forum Report - Exploring the Future of Cloud Computing: Riding the Next Wave of Technology-Driven Transformation [at] World Economic Forum in Partnership with Accenture 2010,

http://www3.weforum.org/docs/WEF_ITTC_Futur eCloudComputing_Report_2010.pdf

(accessed: 10.07.2012).
[34] Xu X. - From Cloud Computing to Cloud Manufacturing [in] Robotics and Computer-Integrated Manufacturing, Vol. 28, 2012, pp. 75-86.

[35] Xu X., Nee A.Y.C. (eds.) - Advanced Design and Manufacturing Based on STEP, Springer Verlag London 2009.

[36] Xu X., Wang H., Mao J., Newman S.T., Kramer T.R., Proctor F.M., Michaloski J.L. - STEPCompliant NC Research: The Search for Intelligent $C A D / C A P P / C A M / C N C$ Integration [in] International Journal of Production Research, Vol. 43(17), 2005, pp. 3703-3743.

[37] Zadeh L.A. - Fuzzy Sets [in] Information and Control, Vol. 8(3), 1965, pp. 338-353. 